Florida International University FIU Digital Commons

7-22-1994

\title{
The relationship of learner entry characteristics and reading and writing skills to program exit outcome
}

Patricia Hayden Allen

Florida International University

DOI: $10.25148 /$ etd.FI13101589

Follow this and additional works at: https://digitalcommons.fiu.edu/etd

Part of the Education Commons

\section{Recommended Citation}

Allen, Patricia Hayden, "The relationship of learner entry characteristics and reading and writing skills to program exit outcome" (1994). FIU Electronic Theses and Dissertations. 1141.

https://digitalcommons.fiu.edu/etd/1141

This work is brought to you for free and open access by the University Graduate School at FIU Digital Commons. It has been accepted for inclusion in FIU Electronic Theses and Dissertations by an authorized administrator of FIU Digital Commons. For more information, please contact dcc@fiu.edu. 


\section{FLORIDA INTERNATIONAL UNIVERSITY \\ Miami, Florida}

THE RELATIONSHIP OF LEARNER ENTRY CHARACTERISTICS

AND READING AND WRITING SKILLS TO PROGRAM EXIT OUTCOME

A dissertation submitted in partial satisfaction of the requirements for the degree of DOCTOR OF EDUCATION

IN

COMMUNITY COLLEGE TEACHING

by

Patricia Hayden Allen

1994 
To: I. Ira Goldenbera

College of Education

This dissertation, written by Patricia Allen, and entitled THE RELATIONSHIP OF LEARNER ENTRY CHARACTERISTICS AND READING AND WRITING SKILLS TO PROGRAM EXIT OUTCOME, having been approved in respect to style and intellectual content, is referred to you for judgement.

We have read this dissertation and recommend that it be approved.

Dr/f Joßeph Cook

Dr. Barry' Greenberg

$\bar{D} \not t$. Janice Sandifbrd

Date of Defense: July 22, 1994

The dissertation of Patricia Allen is approved.

Dean

College, of Educaffion,

Dr. Richard L. Cambell

Dean of Graduate Studies

Florida International University, 1994 
${ }^{\circ}$ COPYRIGHT 1994 by Patricia Allen

All rights reserved 
I dedicate this dissertation in the memories of both my father, Francis Thomas Hayden, and my friend, David Silverstein. Their confidence in me was inspiring. 


\section{ACKNOWLEDGEMENTS}

This dissertation represents the end product of an effort beginning with my parents encouragement of me to pursue first, my Bachelor's, then my Master's, and finally a Doctoral degree. I am grateful to both of them for their support.

I am grateful also to my husband Rick, and my children Patrick, Casey, and Megan for all of their love, patience and constant support during this endeavor. Rick's encouragement and unending support made this goal possible for me in countless ways.

I would like to acknowledge Dr. Joseph Cook, my major professor, who directed this study with patience and understanding. I am grateful for his endless efforts. I also appreciate my committee members', Dr. Barry Greenberg and Dr. Janice Sandiford, assistance, patience, and support.

I would like to thank my typist, Geraldine Plummer. The experience and support were invaluable.

I am especially grateful to my friend and colleague, Dr. Renee Leasure, of the University of Oklahoma for her invaluable comments, insight, unending patience, and support in this dissertation completion. Dr. Leasure's commitment to research was inspiring. 


\section{ABSTRACT OF THE DISSERTATION}

THE RELATIONSHIP OF LEARNER ENTRY CHARACTERISTICS AND READING AND WRITING SKILLS TO PROGRAM EXIT OUTCOME by

Patricia Allen

Florida International University, 1993

Professor Joseph Cook, Major Professor

An approach to enhancing the success of nursing students is found in understanding the learning process and in the academic and sociologic variables placing students at risk for failure and attrition. Utilizing Bloom's Mastery Model, nurse educators may reduce failure and attrition by enhancing alterable variables. This Ex Post Facto investigation utilized Bloom's learning theory to examine a causal relationship of learner entry characteristics, learner reading and writing skills and the impact on program exit grade point average. The study sample was comprised of 143 nursing students entering an upper division urban multicultural baccalaureate nursing program. Data were collected by use of a demographic questionnaire, assessment of reading and writing skills of junior students in the nursing program, and obtainment of the program exit grade point average. A recursive path analysis was utilized for data analysis. 
Findings revealed older male students who transferred to the program from a university with high entry grade point averages excelled in reading assessment scores. University transfer students with a high entry grade point average excelled in writing also. Students for who French, specifically Creole, was a first language had lower writing scores and program exit grade point averages. Spanish as a first language was also associated with lower exit grade point averages. Higher reading and writing scores and entry grade point averages were associated with higher program exit grade point averages. Finally entry grade point average and university transfer were the only entry characteristics mediated by both reading and writing scores. 
CHAPTER

I. INTRODUCTION . . . . . . . . . . . . . . . . . . . . 1

Statement of the Problem . . . . . . . . . . . 4

Assumptions . . . . . . . . . . . . . . . . 14

Research Questions . . . . . . . . . . . 15

Definition of Terms . . . . . . . . . . . . 15

Scope of the Study . . . . . . . . . . . 16

II. REVIEW OF THE LITERATURE . . . . . . . . . . . . 19

Grade Point Average as a

Predictor of Success . . . . . . . . . . 20

Entry Characteristics of

Nontraditional students

Path Analysis for Models in

BSN Education . . . . . . . . . . . . . 34

III. METHODOLOGY . . . . . . . . . . . . . . . 38

Research Method . . . . . . . . . . . 38

The Sample . . . . . . . . . . . . . . . 43

Instrumentation . . . . . . . . . . . . . . 44

Data Collection Procedure . . . . . . . . . . 46

Data Analysis Plan . . . . . . . . . . . . . 47

Methodological Assumptions . . . . . . . . . 48

Methodological Limitations . . . . . . . . . . 48

Human Assurance . . . . . . . . . . . . . . 49

IV. RESUlTS . . . . . . . . . . . . . . . . 50

Description of Sample . . . . . . . . . . . 51

Correlation Presentation . . . . . . . . . . 64

Selected Path Presentation . . . . . . . . . 67

Presentation of Findings . . . . . . . . . . 79

Summary of Findings . . . . . . . . . . . . . 86

V. DISCUSSION

Summary . . • . • . . . . . . . . . . . . . 90

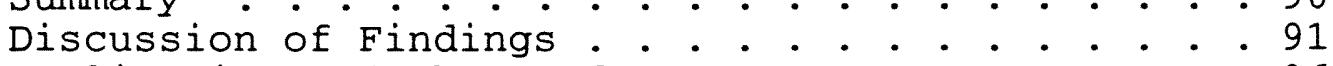

Implications of the Study . . . . . . . . . . 96

Recommendations for Further Study . . . . . . 101

APPENDICES . . . . . . . . . . . . . . . . . 102

REFERENCES . . . . . . . . . . . . . . . . . . 119 


\section{LIST OF TABLES}

Table

Page

1. Nursing Textbook Readability . . . . . . . . . . 11

2. Studies of GPA as a Predictor of Success

in NCLEX-RN 1... . . . . . . . . . . 23

3. Entry Characteristics . . . . . . . . . . . . 52

4. Age of Participants at Program Admission . . . . . 54

5. Ethnicity . . . . . . . . . . . . . . . 55

6. Transfer Institution . . . . . . . . . . . . 57

7. Participant's Language . . . . . . . . . . . . 59

8. Program Entry Grade Point Average . . . . . . . . 61

9. Reading Scores . . . . . . . . . . . . . . 63

10. Writing Scores .. . . . . . . . . . . . . 64

11. Correlation Matrix . . . . . . . . . . . . . 66

12. Transfer Institution's Mean Entry GPA . . . . . . 69

13. Direct, Indirect, and Total Causal Effects . . . . 78

14. Correlation Matrix of Path Variables . . . . . . 89

15. Comparison of Participant's Race to

National Percentages . . . . . . . . . 95 
1. Untested Model of Program Exit Outcome . . . . . . . 42

2. Untested Model of Program Exit Outcome Paths . . . . 71

3. Paths of Emerging Model . . . . . . . . . . . 72

4. Trimmed Model of Program Exit Outcome . . . . . . . 74

5. Research Question 1. Findings . . . . . . . . . 81

6. Research Question 2. Findings . . . . . . . . . . . 83

7. Research Question 3. Findings . . . . . . . . 85 
CHAPTER I

INTRODUCTION

Praxis, the application of theory in practice, is an excellent way to describe teaching. Praxis requires the examination of the interaction of theory and practice and how each influences and shapes the other (Bevis \& Watson, 1989). Exploring actual teaching and learning involves exploring the effect of theory on teaching and learning.

A well-known theory of learning, developed by Bloom in the early seventies and expanded in the eighties, involved a mastery learning model (Bloom, 1976). Key points of this model have been utilized successfully in practice. The empirical base of Bloom's theory concerns what variables make a difference in the determination of instructional outcomes (McCord, 1985).

Bloom's (1976) Mastery Learning Model proposed specific entry characteristics interact with instructional variables to create outcomes of learning. Bloom (1976) placed major emphasis on "alterable variables" for schooling. These alterable variables include "cognitive entry behaviors of students," "affective entry characteristics," and "a number of specific factors making up the quality of instruction." The important feature of Bloom's model is the attention to the study of alterable variables. In addition, Bloom's 
model "proposes that differences in achievement can be reduced over time if there are successive learning units" (McCord, 1985, p. 120). This axiom has been termed the "variation reduction hypothesis." Programs of developmental study in higher education institutions provide testing ground for this theory (McCord, 1985). Identification of learner entry characteristics which are predictive of multicultural nursing students' outcome performance will provide direction for student selection, as well as direction for the development of retention strategies for at risk students. In this investigation the specific learner entry characteristics which correspond to Bloom's model were age, gender, ethnicity, transfer status, previous degrees, English as a second language, and the learned skills of reading and writing were analyzed in relation to the educational outcome, grade point average (GPA). Bloom's model proposes the researcher should investigate what makes a difference in the determination of learner outcomes. Alterable variables in this study were reading and writing skills. These basic skills have been previously documented as weak within this university program and have also been a nationally addressed concern in education today (Allen, Ellis, \& Northrop, 1992).

The United States National Center for Educational Statistics (1991) reports that scores for 9-, 13-, and 17- 
year olds in reading, writing, and mathematics, varied widely from 1984 to 1990. These students are now the current college freshman, sophomores, and juniors. In South Florida, including Dade, Broward, and Palm Beach Counties, tenth graders scored below the state average in areas of reading comprehension and math skills in 1993 (Kleindienst, Rubin, \& Cenziper, 1993) .

In 1993, Florida public school educators also began assessing student writing skills in the fourth, sixth, and eighth grades. In all grades tested, students scored below the national average in writing skills assessment in South Florida. This first essay assessment in writing performed in public education in Florida demonstrated the commitment of the school system to address the complaint by employers that students graduate from school unable to write. (Gittlesohn, 1993) .

Writing is cited by Tomlinson (1990) as a necessary step higher order thinking. Several educators outside of nursing support the notion that writing skills demonstrate thinking skills (Braxerman, 1981; Kinneavy, 1980; Odell, 1980). Writing requires students to take what is already known and enhance reasoning by paraphrasing, questioning, summarizing, and comparing (Tomlinson, 1990). Writing requires the student to think abstractly, conceptualize, reason, interpret, and expand. These skills may have been 
overlooked in an educational arena which supports the old paradigm shift of writing as "writing to learn" (Allen, Bowers, \& Dickleman, 1989).

Multiple choice testing has replaced the essay as the tool for student knowledge assessment. Licensure examinations, course final examinations, and program exit examinations all utilize the multiple choice test question as the tool for knowledge assessment. Writing skills have been replaced by new skills for test success in a multiple choice testing environment where test-taking strategies are encouraged and the student becomes test wise.

Statement of the Problem

An approach to enhancing the success of nursing students is found in understanding the learning process and in the academic and sociologic variables placing students at-risk for failure an attrition. In order to improve retention of "at risk" nursing students, accurate tools for improved decision making regarding methods for both enhancing the success and reducing the attrition and failure rates within selected schools of nursing are needed. A model for more accurately predicting academic achievement among nursing students will enhance success; reduce attrition, and reduce failure rates within selected schools of nursing. Utilizing Bloom's Mastery Model, nurse 
educators' may reduce failure and attrition by enhancing alterable variables such as reading and writing skills.

Utilizing Bloom's learning theory and the current available literature on the diverse and unique learning needs of today's college student, this investigation explored a causal relationship of specific learner characteristics to program exit GPA. What specific learner entry characteristics including reading and writing skills are direct and/or indirect predictors of program exit grade point average in an urban multicultural baccalaureate upper division nursing program?

\section{Purposes of the study}

This study was conducted to further relate learning to practice. Utilizing components of Bloom's learning theory the investigator explored the causal link between learner entry characteristics, reading and writing skills, and program exit grade point average. The study explored the relationship of reading and writing skills and learner entry characteristics to academic achievement in a selected baccalaureate nursing program.

\section{Significance of the Program}

This investigation examines the importance of demographic and academic background factors on the effect of 
program exit grade point average in an urban multicultural upper division baccalaureate nursing program. Social factors to be investigated by this investigator include the learner's age at admission, gender, ethnicity, previous school transferring from, previous degrees, English as a second language. The academic variables for investigation include entry grade point average, reading skill score, and writing score. The setting for this research was chosen specifically for its cultural diversity and complexity. As changing economics and cultural diversity increasingly impact the national higher education system, the nontraditional student found in heavily populated areas such as New York, California, and Florida is the student of tomorrow for other higher education settings. It is projected by the year 2000, over twenty million nontraditional students will be on the college campuses (Stage \& McCafferty, 1992). South Florida public higher education is represented by the nontraditional college student. This investigation identified the paths to success for the learner of tomorrow by identifying positively and negatively correlated variables in the path to program exit out come.

Where to begin to teach and applied discipline such as nursing is always a difficult and complex issue for nurse educators. How to strike at a given level for learning 
episodes is a difficult question for educators (Bevis \& Watson, 1989). Numerous factors affect the teaching strategies utilized by educators. Learner entry characteristics and academic skills such as reading and writing do alter the learning event or episode for the group and should be addressed. Enlightenment on the specific role these variables play in the educational outcome will enhance the planning for learning episodes by nurse faculty preparing nursing students for both professional practice and successful completion of the state licensure examination.

State licensure is the goal of all generic BSN graduates. Licensure is the key to practice as well as graduate education. The process of nursing licensure has undergone many changes in the past 30 years. In 1955, the National League for Nursing (NLN) passed control of the licensure testing to the American Nurses Association, who based the exam on five subject areas for testing. The National Council of State Bards of Nursing began developing and implementing the examination in 1972 and this organization developed a new exam in 1982 titled the National Council Licensure Examination for Registered Nurses (NCLEX-1) which changed the testing format from five specific content areas to a test of the integrated practice of nursing (Wall, Miller, \& Widerquist, 1993). The National 
Council again changed the test following a job analysis in 1986. The new NCLEX-2, implemented in 1988, is based on the nursing process, has 100 fewer questions and a higher passing standard, reports the score as only pass or fail, and is focused on client needs (Bosma, 1990). The most recent job analysis was done in 1990 and based on these findings no exam changes were made. In 1991, the National Council of State Boards of nursing voted to change the test from a paper and pencil test to a computer adaptive test (CAT) format and this test was piloted in 1993. This test will be implemented in 1994 (Wall, Miller, \& Widerquist, 1993).

In 1988 the lowest pass rate in seven years was reported on the National Council Licensure Examination (NCLEX) for Registered Nurses (Ashley \& O'Neil, 1991). These decreasing pass rates coincided with the new NCLEX-2 exam implemented in 1988. Prior to the new CAT test, the examination was given twice a year. The results from an NCLEX profile of percent passing nationally reveals baccalaureate nursing students from July 1991 to July 1993 scored below the national passing percentage for all graduates taking the examination. The BSN graduates scored two percentage points below the national average of all graduates taking the examination (NCLEX Summary, 1993). The National Commission on Excellence in Education in 
1983 reported academic qualifications of college entrants, including those from nursing, decreased significantly. In 1990, the U.S. Department of Education reported the reading, writing, and mathematics skills and Scholastic Aptitude Test (SAT) scores have declined over the past 20 years. The strength of SAT scores is relevant beyond the basic knowledge this test measures. SAT scores suggest the student's ability to process information and student's test taking ability (Younger \& Grap, 1992). SAT verbal skills are tested through the students reading ability, an important variable of this study. This decline in the basic academic skill of verbal ability of entering nursing students presents a problem for nurse educators.

Nursing textbook readability was obtained by evaluating samples of the nursing program textbooks utilizing the program Grammatik 5 in the technical reading evaluation made (WordPerfect, 1993). A paragraph from each text chosen at random was evaluated in Grammatik 5. A comparison of the results of the Grammatik analysis is shown in Table 1. The nursing textbooks chosen were in use at the time of the sample's educational experience. The textbook mean from this sample of four major textbooks utilized by this nursing program were at grade level 11.82. Utilizing a second readability analysis program the same four textbook samples required a mean grade level of 15.25. The second computer 
program analysis was done with Correct Grammar medical edition for DOS. Both readability program analyses revealed all four textbooks had Flesch Reading Ease scores of difficult to very difficult. It is important for entering junior students to have a reading ability at or above the level of textbook use. The current trend toward a decrease in academic qualifications may make textbook comprehension more difficult. 
Table 1

Nursing Textbook Readability

\begin{tabular}{lcc}
\hline TEXTBOOK & $\begin{array}{c}\text { GRADE } \\
\text { LEVEL }\end{array}$ & READING EASE SCORE \\
\hline $\begin{array}{l}\text { Fundamentals of Nursing } \\
\text { (Kozier, Erb, \& Olivieri) }\end{array}$ & 9 & 6 to 10 years of schooling \\
$\begin{array}{l}\text { Medical-Surgical Nursing } \\
\text { (Ignatavicius \& Bayne) }\end{array}$ & 16 & More than 10 years of schooling \\
$\begin{array}{l}\text { Nurse's Manual of } \\
\text { Laboratory Tests } \\
\text { (Cella \& Watson) }\end{array}$ & 20 & More than 10 years of schooling \\
$\begin{array}{l}\text { Nursing Diagnosis } \\
\text { (Carpenito) }\end{array}$ & 12 & More than 10 years of schooling \\
Textbook Mean & 11.8
\end{tabular}

Nurse educators are given the task of guiding nursing students to process basic knowledge and transfer knowledge from course to course in a curriculum moving from simple to complex; in order to apply concepts in a practice discipline. Decreasing academic qualifications of college entrants substantiates the need to collect more data on variables contributing to the success or failure in baccalaureate nursing education; thus, signaling educators to early intervention for at-risk nursing students.

Baccalaureate nursing programs have many paths to completion. Nursing curricula may begin at various levels of a four-year program. The student may begin nursing courses in the freshman year while taking prerequisite 
courses or the nursing course work may begin in the second year of college with sophomore admission to the nursing program. The program in this investigation is similar to a two plus two program or upper division program. The student is admitted to the school of nursing at the beginning of the junior year following completion of all prerequisite coursework. In this type of nursing program the student either completes two years of coursework at a community college or university and then applies for admission to the upper division nursing program. Students who are admitted to the nursing program participate in an intensive course of study their junior and senior year.

Upper division baccalaureate nursing programs of study are concentrated in the last two years of university study. Attrition at this point of progression in the student's education is a costly problem for all concerned. Families, students, and schools of nursing, as well as the community caught in a new baccalaureate nursing shortage, all suffer a loss when student attrition occurs. Faculty awareness of student characteristics and basic skills may enhance student success. Gathering objective information which provides insight regarding the "at-risk" student is far superior to advisement of students solely on faculty intuition of student needs (Huch, Leornard, \& Gutsch, 1992).

Recently, many investigations have focused on 
assessment of learner readiness and characteristics of learners resulting in successful program completion. Numerous correlational studies of nursing students' characteristics and their National Council Licensure Examination (NCLEX-RN 1) pass rates have been explored (Fowles, 1992; Payne \& Duffy, 1986; Yang, 1987). These correlational studies have chosen a sample of traditional nursing students from the population for study. The nontraditional nursing student, the student nurse applicant of the late eighties and nineties, was the target population chosen for this investigation. The sample for this study is found in many urban, multicultural coastal settings, especially in South Florida.

The subjects of this study were comprised of students from a South Florida baccalaureate nursing program. These students were impacted by many factors extraneous to the classes being conducted, such as economic difficulties, English as a second language, and family commitments. This Baccalaureate School of Nursing (BSN) has been accredited by the National League for Nursing with a curriculum accreditation extending until the year 2002. The history of this baccalaureate program has shown a faculty who consistently strived to meet the needs of this very diverse population. Students in this program have access to "within group" peer tutors, reading and writing assessment 
by the learning laboratory faculty, follow-up by the learning lab faculty for specific student needs, math remediation tutoring sessions, and advisement for financial assistance are available. Entry characteristics and previously learned reading and writing skills may well be stress for educational enhancement for the student entering an intensive five-semester upper division program of nursing study. The exploration of a prediction model for this program was useful in targeting specific assessment measures currently based on faculty intuition rather than research findings. Although using a prediction model does not remove all uncertainty of student success, it provides objectivity in student selection and provides direction for referral for student academic needs in reading and writing skills. Path analysis does not look at predictor variables in single pairs, instead, path analysis provides a more comprehensive picture of the influence of groups of variables on the dependent variable or, in this case, exit grade point average.

\section{Assumptions}

This study was based on the following assumptions:

1. The applicant pool arrives with a range of diverse entry characteristics.

2. The applicant pool arrives with a range of reading 
and writing skills.

3. Reading and writing skills are necessary tool for academic success and professional nursing practice.

\section{Research Questions}

The research questions which were tested at the $p<.05$ level of significance were:

1. What is the relationship between learner entry characteristics and reading and writing scores?

2. What is the relationship between reading and writing scores and program exit grade point average?

3. What is the relationship between learner entry characteristics and program exit grade point average?

\section{Definition of Terms}

Learner Entry Characteristics: Characteristics of the participants included entering GPA, transfer status, gender, English as a second language, and age. Selected Baccalaureate Nursing Program (BSN): An upper division urban multicultural baccalaureate nursing program with greater than $90 \%$ of the applicant pool flowing from two urban multicultural community colleges. Upper Division: Students who are eligible for first semester junior year status and who will complete five semesters in the program. 
Reading and Writing Assessment: The screening tests administered by the Campus Learning Laboratory Faculty in the first semester of nursing school. Program Exit Grade Point Average GPA: The grade point average at graduation for the selected program based on a four point scale.

Native Student: A student now in the upper division program who completed the first two years of lower division work at this university.

Non Native or Transfer student: A student who transfers into the university from another university or community college in the junior year for BSN obtainment.

Scope of the Study

This study identified causal relationships existing between learner entry characteristics, reading and writing skills, and program exit grade point average. The study sample was limited to one urban upper division baccalaureate nursing program with entering juniors for four consecutive classes composing the sample. No attempt was made to identify the impact of exogenous variables such as the rigor of the nursing curriculum on program exit grade point average. Although an important component of exit grade point average, the nursing content knowledge is not a concept of Bloom's Mastery Model and was not considered in 
this study This study examined the alterable variables of entry characteristics and previously learned skills in relation to grade point average.

Limitations and Delimitations

1. Those imposed by operational definitions as indicated by the definitions of terms.

2. The population in this study represented only a small number of the nontraditional baccalaureate nursing students in the United States.

3. The study sample was generated from only one metropolitan area and may not be representative of the total population of baccalaureate nursing students.

4. In this retrospective study, the instruments chosen by the Campus Learning Laboratory Faculty to evaluate nursing students' reading skills did not have established reliability and validity for any population.

5. Attitudes toward evaluation type instruments may have been transferred to the demographic questionnaire and the reading assessment test.

6. The nursing content knowledge obtained from admission to program exit was viewed as an exogenous variable; although noted, this was not 
assessed in relation to Bloom's Mastery theory and the dependent variable of program exit grade point average. 
CHAPTER II

REVIEW OF THE LITERATURE

Nurse educators, specifically baccalaureate nurses educators, are very interested in mechanisms for enhancing the success of incoming nursing students. By enhancing the success of incoming nursing students educators may decrease student nurse attrition from baccalaureate nursing programs. An approach to enhancing the success of nursing students is found in understanding the learning process and in the academic and sociological variables placing students at risk for failure or attrition. Numerous studies have addressed these concerns in the last decade. In reviewing the literature, the majority of the research in the area of retention has occurred in the last five to seven years following the NCLEX examination blueprint change and the influx of the nontraditional nursing student into baccalaureate nursing programs.

This literature review explored current nursing education research in three important, interrelated areas. First, current research on grade point average (GPA) as a predictor of academic success was being explored. Next, the entry characteristics of the nontraditional nursing student, including reading and writing skills of this population were reviewed. And finally, the use of path analysis or causal modeling in higher education, particularly baccalaureate 
nursing education, was summarized.

\section{Grade Point Average as a Predictor of Success}

The need to research this area of academic and nonacademic factors in student success appears form the literature review to have occurred as a direct result of the increase in National council Licensure Examination-RN (NCLEX) exam failures over the last five to seven years (Ashley \& O'Neil, 1991; Bosma, 1990). Nursing, a practice discipline, has traditionally utilized NCLEX pass rates of a program as evaluation criteria or program outcome measurement to support the success of the nursing program.

Several studies began as correlational investigations to find the key piece of testing data which might predict success on the NCLEX (Foti \& DeYoung, 1991; Glick, McClelland, and Yang, 1986; Horns, O'Sullivan, \& Goodman, 1991; McKinney, Small, O'Dell \& Coonrod, 1988; Whitley \& Chadwick, 1986; Yang, Glick, \& McClelland, 1987). As studies were replicated and interest grew, only one variable could be identified as an academic predictor of success. This variable appears from the literature review to be grade point average (GPA). GPA is consistently reported as a predictor for performance on the NCLEX examination (Dell \& Valine, 1990; McKinney, Small, O’Dell, \& Coonrod, 1988; Quick, Krupa, \& Whitley, 1985; Wall, Miller, \& Widerquist, 
1993).

Students have many opportunities to generate a GPA. Research investigations have varied on the selection of which student GPA is the best predictor. Table 2 reviews the numerous investigations reported in the literature to support GPA as a predictor of success. Many studies cite entry GPA, Pre-nursing GPA, Nursing GPA, Science course GPA, Nursing Theory GPA or Cumulative GPA as the key predictor variable for NCLEX correlation. To summarize Table 2, 7 of the 12 studies noted found pre-nursing GPA or entry GPA to be the best predictor of success on the NCLEX-1 examination.

In a comprehensive study recently published in the literature with a sample size of 1,069 graduates, the prenursing GPA emerged as one of the best predictors of academic success (McClelland, Yang, \& Glick, 1992). The results were obtained from a sample of nursing students between 1985 to 1988 ; therefore, the results reflect success on the first NCLEX-RN, the examination after 1988 had an increase in content difficulty and caution must be used in generalizing these results. This particular study is the third investigation into academic variables by these investigators and the high predictability of pre-nursing GPA has emerged as a predictive variable in all three studies (Glick, McClelland, Yang, \& Glick, 1986; McClelland, Yang \& Glick, \& McClelland, 1987). Pre-nursing or entry GPA is one 
of the entry characteristics for review in this proposed model.

The conflict to note with the investigations reviewed concerns the change in the content of the NCLEX-RN exam in 1988. These studies were all based on NCLEX-RN results of testing from 1982 to 1987 . The results now are only reported as pass/fail and no numerical value is reported to the examinee or school of nursing. 
Table 2

Studies of GPA as Predictor of Success on the NCLEX-RN \#1

Name of Study

Whitley \& Chadwick (1986)

Payne \& Duffy (1986)

Glick, McClelland, \& Yang

Yang, Glick, \& McClelland (1987)

McKinney, Small, O'Dell,

\& Coonrod (1988)

Froman \& Owen (1989

Feldt \& Donahue (1989)

Horns, O'Sullivan, \& Goodman (1991)

Foti \& De Young (1991

Fowles (1992)

McClelland, Yang, \& Glick (1992) Pre-NSG GPA

Wall, Miller \& Widerquist (1993) Core GPA

\section{Predictors of Success}

Cumulative GPA, Sci GPA

Pre-NSG GPA, NSG GPA

NSG GPA

Pre-NSG GPA, Chemistry GPA

Pre-NSG GPA, NSG GPA

NSG GPA

NSG GPA

Pre-NSG GPA

Cumulative GPA

1st Semester NSG GPA

\footnotetext{
* Sci GPA (Science GPA)

*Pre-NSG GPA (pre-nursing GPA)

*NSG GPA (Nursing GPA)

(Prerequisites)

*Core GPA

**Adapted from Wal1, Miller, \& Widerquist, (1993). Predictors of Success on the Newest NCLEX-RN.

Western Journal of Nursing Research, 15(5), 632 .
} 
Two reported investigations (Wall, Miller, \& Widerquist, 1993; Waterhouse, Carroll \& Beeman, 1993) have been done on the predictors of success on the newest NCLEX2RN examination. The first investigation reports core GPA to be an indicator of success on the new NCLEX. In addition, in this study, scores on the National League of Nursing achievement tests are also an indicator of success on the new NCLEX-2 (Wall, Miller, Widerquist, 1993). The study sample size was small with only 92 participants and only 86 participants for some of the 10 independent variables where data were unavailable.

The second post 1988 NCLEX2-RN examination study (Waterhouse, Carroll, \& Beeman, 1993) explored the NCLEX-RN results with a sample of 257 and noted accurate predictive data on student success on the NCLEX is available by the end of the junior year with what is referred to a "grade point index". However, the investigators again report the best predicator on NCLEX-RN success is the graduation grade point average. The study was unable to predict the outcome for $20 \%$ of the students who ultimately failed the NCLEX. This finding leads one to question that although GPA is a strong indicator of licensure success, there are still other predictors not yet delineated.

Grade point average as an indicator of success was briefly explored as it related to prediction of the high- 
risk college student's success. One comprehensive study of 1235 first-year college students determined the relationship of high school achievement, certain nonacademic factors, and the student's first semester college performance (Larose \& Roy, 1991). These researchers reported high school grade point average appeared to be less predictive of success at the college level for students with poorer academic records. Certain nonacademic predictors appear to be better predictors of success for this group of college students. Community college grade point average was a final area for review for the proposed study. In a study of California community colleges' level of student learning, Ratcliff (1992) noted academic performance, specifically GPA, was related to gender with $65.8 \%$ of the transfer group being female. Also ethnicity, major, and educational attainments of parents demonstrated a positive correlation to student achievement.

Entry Characteristics of Nontraditional Nursing students Grade point average has been well documented as a key aspect of goal attainment or licensure, but what is the relationship of other variables impacting the student experience? Responding to this question, the research area broadened, and researchers began to investigate what nonacademic variables may enhance success in nursing school 
well as performance on the licensing examination for professional nursing.

Recent studies have correlated nonacademic variables in an attempt to identify students at risk for program failure or attrition. Chacko and Huba (1991) stated "If all students arrived with the same tools for success then reducing student attrition would not be one of the major concerns of nurse educators today" (p. 267).

If the academic attributes for success are clearly predictable, then enhancing the basic skills is the obvious answer. However, researchers point out there is clearly something more than academic preparedness enabling the student to succeed (Clowes, 1980; Larose \& Roy, 1991; Levin \& Levin, 1991). Could these non-academic factors or characteristics on program entry also be predictors of success?

Not surprisingly, the literature has long supported the notion that pre-entry characteristics of student ability and past performance are associated with retention of students (Astin, 1975; Benda, 1990; Higgs, 1984; Johanssen \& Rossman, 1973; Redman, 1986). In separate studies, Redman (1986) and Higgs (1984) found a key predictor of success in the upper division program to be whether the student had taken prerequisites at a junior or senior college. Junior college transfer students had higher rates of attrition reported; 
however, Ratcliff (1992) in a review of the California community colleges did not find the transfer student to be deficient in any way. This may be due to improved articulation agreements between two and four-year colleges from the findings of the mid-eighties to the current study of 1992. This may also be attributed to a changing student population, a better prepared student or other yet unstudied predictors.

The traditional student in nursing in the past has been female, Caucasian, and between the ages of 18 and 23 . Nursing school enrollment decline in the early eighties and the state of the economy over the past decade have enabled a new student nurse applicant to emerge in upper division nursing programs. This new student has been labeled in the educational and nursing literature as the "nontraditional" student who varies from past applicants in age, previous life experience, gender, and ethnicity. This applicant is no longer a native student in an upper division program, but in many cases is a transfer student from a two-year program at a local community college. This student is probably not living in the campus dorm involving his entire day in a campus environment. He/She may live and work full-time off campus, is an older student, a working parent or often foreign born (Wolahan, \& Wieczorek, 1991).

This investigation setting is parallel to the setting 
discussed in the recent research of educational enrichment by Wolahan, and Wieczorek, (1991). In this study, the population has a large number of Hispanics and Caribbean born students. Many enroll in nursing as a route to upward mobility and economic independence (Johnstone, 1989).

"These nontraditional students will be increasingly minority adults with family responsibilities, of different cultures where English is a second language (ESL), have varied educational backgrounds, and be more likely to attend school part-time" (Moccia, 1989, p. 15).

The literature reveals culturally different students encounter a multitude of difficulties from academic underpreparedness to "psychological, social, cultural, and economic stress" (Wolahan, \& Wieczorek, 1991, p. 234). This population enters the educational setting with a wealth of life and work experiences, yet theory knowledge is weak and the student may have difficulty conceptualizing, transferring information, and problem-solving (Thompson \& Crutchlow, 1993).

One entry characteristic not well reviewed in the educational literature appears to be ethnicity. Educators might expect with the increase in cultural diversity of the student population the literature would address this learner characteristic. This has not been the case as determined by the literature review. Insufficient information is 
available for faculty meeting the challenges of the English as a Second Language (ESL) student (McLeod \& Kreitlow, 1991; Phillips \& Hartley, 1990; Shearer, 1989).

Ethnicity as a student characteristic is a timely topic for adult education research. Nontraditional students with a cultural difference are not graduating from nursing schools in proportion to their representation to the population; minorities have been reported to experience disproportionately higher attrition rates than traditional students (Phillips \& Hartley, 1990). Nakanishi (1990) reviewed five major education journals over a ten-year span from 1976 to 1986 and found only one brief article on refugees and immigrant populations. Ross-Gordon (1991) noted only 18 of the education research literature brings up one or more of the multiple ethnic groups in the U.S. from the year 1985 to 1990. Yet the changing candidate pool has been noted often in the literature with $3 \%$ of nursing students nationwide reported to be Hispanic and $4.5 \%$ American Indian or Oriental (Farrell, 1988). Recent National League for Nursing (1992) statistics indicate of all students enrolled in collegiate programs only $18 \%$ are minority; with $11.1 \%$ Black, 3\% Asian, $3.2 \%$ Hispanic, and 0.58 Native American students.

These percentages are inconsistent with the nursing education agenda for the nineties goal which are, 
specifically; to increase cultural diversity in nursing education in both curricular content and in student population (NLN, 1992). This goal is formulated in a time when multicultural nursing students are not graduating from U.S. nursing programs in proportion to their representation in the nation's population (Tucker-Allen, 1989).

of particular importance to note in this exploration will be the student who attended grade school outside of the U.S. and utilizes a language other than English. Memmer and Worth (1991) found difficulties for these students most obvious in the areas of reading, listening, speaking, and writing. ESL, reading ability, and writing ability will be important predictor variables in this current investigation.

Although the literature review yields conflicting information of the best predictors of academic success, past academic achievement as indicated by entry GPA and reading skill may be the two strongest predictors of success noted in the literature to date (McClelland, Yang, \& Glick, 1992). These two variables do appear to be linked when reviewing the research done by Symons and Pressly (1993). This investigation found prior knowledge affects text search success and extraction of information. Reading to locate information requires selective sampling of the text, a skill distinct from reading comprehension (Symons \& Pressly, $1993)$. 
Reading skill has been measured in varying ways in the studies noted. SAT verbal score is one method, Asset test scores note reading ability, and the Nelson-Denny Reading Test are all tools utilized for reading assessment of incoming students.

Chacko and Huba (1991) presented a model of academic achievement among nursing undergraduates depicting three cognitive variables; reading ability, language ability, and math ability as well as two affective variables, life stress and motivation. Although the setting varied from this proposed investigation and the sample of Chacko and Huba was from a two-year community college nursing program, the results help delineate the need for this current investigation. The model which emerged for these researchers depicted reading ability and language ability to be directly related to academic achievement. This supports the assumption that current achievement is influenced by previous achievement and reading has been noted in the literature as an appropriate cognitive variable to assess for incoming nursing students (Chacko \& Huba, 1991; Colombraro, 1990; Foti \& DeYoung, 1991).

Foti and DeYoung (1991) in the previously noted study on predicting NCLEX-RN success found SAT verbal score as part of a constellation of predictors for licensure success along with GPA. The study sample of 298 was drawn from the 
school of nursing where the investigators taught. The faculty had supported emphasis on reading skills and required entering nursing students to be tested with the widely known Nelson-Denny Reading Test. Scores below the fifth stanine on vocabulary and reading were referred to an academic enrichment program. Reading assessment for entering nursing students was noted in several other studies reviewed in the literature with the Nelson-Denny Reading Test appearing to be the tool of choice for most programs (Campbell \& Davis, 1990; Wolahan \& Wieczorek, 1991).

Writing, the other basic skill for investigation in the proposed study, has been very briefly addressed in nursing education research. Students of nursing, science, and professional schools all have documented decline in writing skills between entry and graduation (Allen \& Diekelmann, 1989). Nursing students have been characterized as "doers" who prefer action to reflection (Heinrich, 1992). Many educators believe writing skills are thinking tools, although the research of this basic skill for success in nursing school is very sparse.

Four studies were located in the literature review pertaining to writing. Three qualitative approaches to investigating the role of writing in baccalaureate nursing programs researched the composing process of nursing students in writing nursing notes, the process of writing 
and the discovery of meaning for the nursing student in this process, and the use of journaling by nursing students (Bradley-Springer, 1993; Heinrich, 1992; Sorrell, 1991). Although the purposes and methods of data collection varied for each of these three studies, an interesting finding of these studies was "writing assists the student to clarify and remember facts." This process of reflection while writing enhances learning. Writing requires reflection by gathering what we already know and adding to it thorough paraphrasing, questioning, and summarizing. In this process of reflection, writing and rewriting enables new concepts to unfold and become our own.

One study utilized a quantitative approach to describe the effect of writing across the curriculum techniques to describe students' attitudes toward and a critical understanding of nursing research (Slimmer, 1992). Here writing was used to promote learning and critical thinking. The findings of this study were not significant, in addition, the sample size was small with only 17 participants.

No studies correlating writing as a predictor of success in nursing school were noted. Writing is a basic skill of each entering nursing student and the ability to write may be a predictor of success not yet explored in the nursing literature. 
Path Analysis for Models in Baccalaureate Nursing Education

Path analysis is a relatively new statistical data analysis technique. The geneticist, Sewall Wright (1921), developed this as a "method for studying the direct and indirect effects of variables hypothesized as causes of variables treated as effects" (Pedhazur, 1982, p. 580). Wright, in his description of path analysis noted path analysis is not a method to determine causation from the values of correlation coefficients. It is intended to provide quantitative information for a method for organizing data and making sense out of variables which may be confusing and overwhelming (Munro \& Page, 1993).

These variables are depicted graphically in the path diagram, although this is not essential for numerical analysis (Pedhazur, 1982). The path diagram does provide the researcher a way to think about the variable relationships and in this case a recursive path diagram is utilized.

Recursive path diagrams have no causal feedback loops and the causal flow is unidirectional (Wolfe, 1985). The use of recursive path models began in the 1970s in higher education by such investigators as Spady (1970) and Tinto (1975) who developed causal models of persistence of students in higher education. Munro (1981) tested Tinto's model in a study of the high school graduates of 1972 and 
found educational aspirations were more than academic integration as Tinto had proposed. This model of Tinto's linking causal relationships of variables to college withdrawal has been replicated by numerous investigators into the 1980s (Bean, 1980; Bean, 1982; Pascarella \& Chapman, 1983).

In reviewing the literature on path analysis in educational research, an investigation of students' characteristics that facilitate the transfer from two- to four-year colleges was particularly relevant to this current investigation (Lee \& Frank, 1990). In this study of 2,500 1980 high school graduates, factors describing the students' academic performance in community college were the strongest direct predictors of transfer to a four year program, but family background and academic orientation in high school had indirect effects. This study noted socioeconomic status, minority status, and gender all impacted transfer to a four-year school. This study was of interest for its use of path analysis in higher education, but also because several of the predictor variables noted in this model are variables of this current research. Transfer status, gender, age, ethnicity, and GPA are all predictor variables of this current investigation and were noted by Lee and Frank in the 1990 study of transfer characteristics. Many causal models were also noted in the specific 
nursing research literature. Several studies utilizing path analyses explored relationships in health behavior models (Cox \& Farrand, 1993; Johnson, Ratner, Bottorff \& Hayduk, 1993). Nursing research has also utilized path analysis to examine the influence of gender on exercise determinants (Hawkes \& Holm, 1993). These studies noted are from a clinical nursing research perspective and confirm the varied uses of path analysis an causal modeling in nursing research.

Nursing education research has utilized this technique of data organization and analysis in a recent study to link the conceptual career paths of doctorates in nursing (Lash, 1992). This research presents a cumbersome path diagram in need of further trimming and presentation of the numerical finds of the direct, indirect, and overall effects of this model.

Two studies utilizing path analysis from nursing education research were noted in the literature search and have specific ramifications for this proposed study (Froman \& Owen, 1989; McClelland, Yang, \& Glick, 1992). Each of these studies finds further delineate the need for this proposed investigation.

In the first study, Froman and Owen (1989) utilized path analysis to predict performance on the NCLEX-RN \#1 exam. The trimmed path diagram presented in this research 
correlated causal influence of age and transfer status influencing GPA in three areas, general GPA, nursing GPA and clinical nursing GPA with only nursing GPA influencing NCLEX outcome. Age was the only predictor variable not mediated by GPA and had a direct effect on NCLEX outcome. GPA on admission, transfer status, and age are three predictor variables of this current investigation.

The second important path analysis investigation conducted by McClelland, Yand, and Glick (1992) noted knowledge of performance indicators can facilitate admission criteria and appropriate resource referral to develop nursing competence in a path analysis of 1,069 graduates. In this study the trimmed model revealed only biology GPA had a direct effect on NCLEX outcome. The model proposed by these researchers for further study includes admission GPA, personal aspirations, personality traits, and socioeconomic status for future study.

Although entry GPA, ESL, transfer status, gender, ethnicity and age have all been research foci of nursing education researchers in the late eighties and early nineties; the literature search did not reveal a path analysis of entry characteristics, basic skills, and program exit outcomes. This is a related, yet new area for research in nursing education. 
CHAPTER III

METHODOLOGY

Ex Post Facto research is one of two nonexperimental broad classes of research. The translation of ex post facto means after the fact. This research was conducted after "the variations in the independent variable had occurred in the natural course of events" (Polit \& Hungler, p. 141).

\section{Research Method}

An approach to enhancing the success of nursing students is found in understanding the academic and sociologic variables placing students at risk for failure and attrition. Utilizing previously supported theory, specifically Bloom's Mastery Model, nurse educators, may reduce failure and attrition by enhancing success, reduce attrition, and failure rates within selected schools of nursing. This investigation examined a path of causal relationships which exists among a set of learner variables which occurred in a specified sample of an upper division multicultural baccalaureate nursing students. The specific type of path analysis chosen for data analysis was a recursive path model described by Kenny (1979) and Pedhazur (1982). In this unidirectional model a variable cannot be both the cause and an effect of another variable. Causal 
models allow the assessment of hypothesized links and force the researcher to confront his model of reality (Wolfe, 1985). A causal model depicted in the Figure 1 displays the mediator variable, scores for basic skills of reading and writing. The mediator variables influences the relationship between the predictor variables, entry characteristics, and the outcome variable, program exit GPA. This model does not depict the exogenous variable (the variable whose variance is accounted for outside the model), nursing content knowledge. Nursing content knowledge is an obvious component in program exit outcome, but not a concept of Bloom's Mastery Mode.

The model flows from the three theoretical concepts identified by Bloom (1976) in his mastery model which proposes learner entry characteristics and previously learned skills are important variables in the student educational outcome. In Figure 1, learner entry characteristics were age, gender, transfer status, English as a Second Language (ESL), and entry GPA. These were also exogenous variables because the variables causes emerge from outside of the model. These exogenous variables have an unanalyzed correlation, the linkage between these variables was left as ambiguous: the covariation among these variables the covariation may be causal or spurious, and the direction of causation among these variables is undetermined 
(Pedhazur, 1982). The previously learned skills were the scores obtained on reading and writing assessment tests upon entry into the selected school of nursing. These scores of reading and writing were considered in this model to be endogenous variables or variables whose variance are accounted for by either exogenous or endogenous variables in the model. These reading and writing scores are also considered to be mediator variables and influence the relationship between the predictor variables, entry characteristics, and the outcome variable, exit GPA (Lindley \& Walker, 1993). These variables are represented by the single-arrow straight line in Figure 1. Finally, the educational outcome concept was represented by the program exit grade point average upon graduation and/or withdrawal from the selected school of nursing and was an endogenous variable.

The recursive path model utilized to test the following research questions at the $\mathrm{p}<.05$ level of significance:

1. What is the relationship between learner entry characteristics and reading and writing scores?

2. What is the relationship between reading and writing scores and program exit grade point average? 
3. What is the relationship between learner entry characteristics and program exit grade point average? 
BLOOM'S LEARNING MODEL
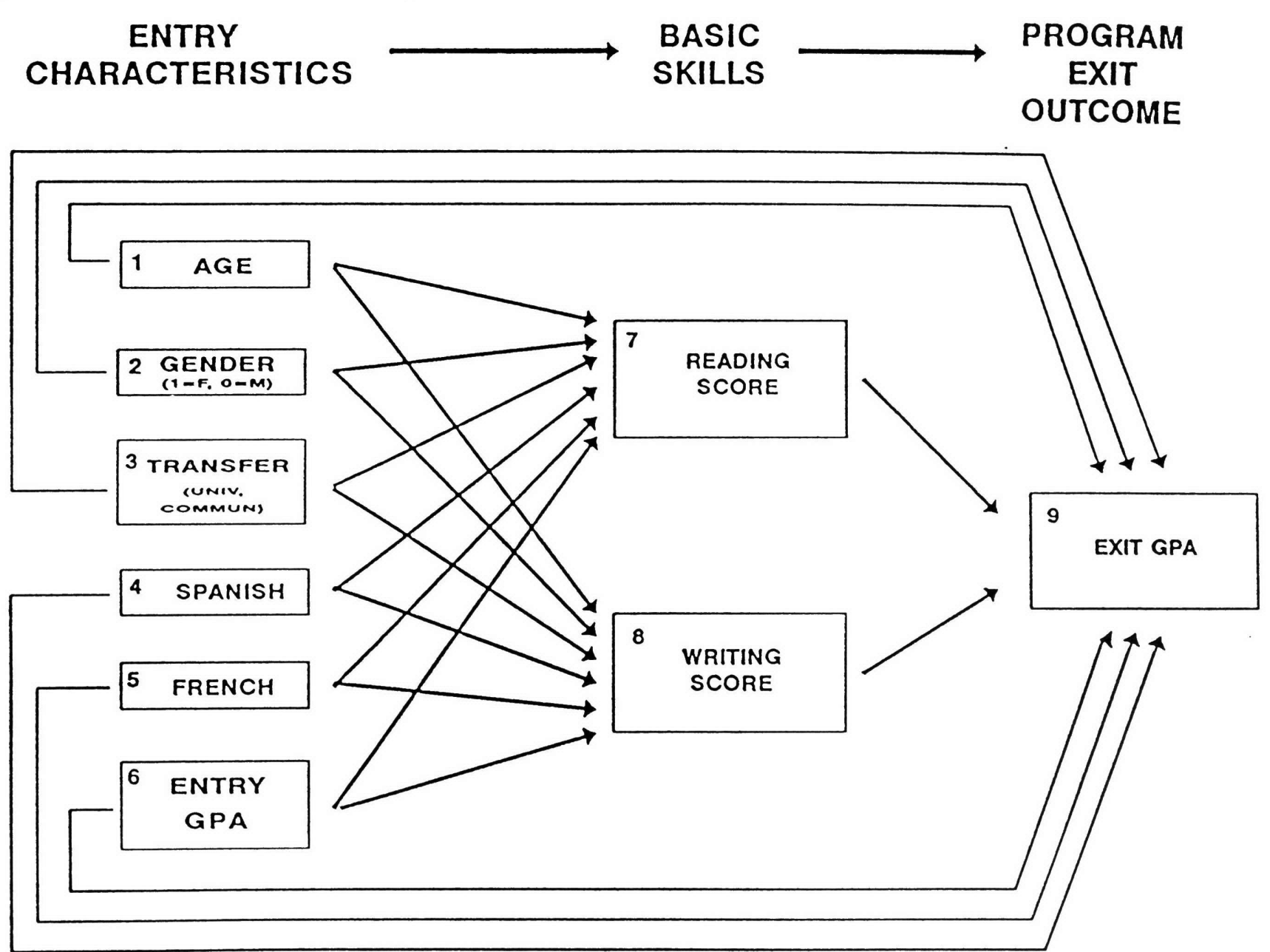

FIGURE 1. UNTESTED MODEL OF PROGRAM EXIT OUTCOME 
The Sample

The study sample were all upper division baccalaureate nursing students enrolled in one South Florida program. The sample will consist of $90 \%$ transfer students from two area community colleges. Native students composed $10 \%$ of the sample. All entering juniors of the class of 1990, 1991, and 1992 were included in the sample, who had taken the reading and writing assessment test. The sample total was 143 first semester junior nursing students who have taken the reading and writing assessment tests give by the Campus Learning Laboratory faculty of a South Florida state university.

A power analysis for a sample size of 136 with 9 variables, an effect size of 0.2 and an $R$ squared of .16 yielded a power of .94 (Cohen, 1987). This $r^{2}$ was chosen because the $r^{2}$ value ranged from .16 to .32 depending on which regression was utilized. The effect size increased from .20 to .40 with the $r^{2}$ of .32 and the power increased to 1.00. Munro and Page (1993) describe power as the likelihood of rejecting the null hypothesis or avoiding a Type II error. Power is related to the sample size, effect size, and significance level. Major work in the area of sample size was done by Jacob Cohen (1987). A $80 \%$ level is generally adequate for a power analysis with effect sizes 
ranging from a small effect as 0.2 of a standard deviation to a large effect as 0.8 .

\section{Instrumentation}

Entry level characteristics were gathered by a participant completed questionnaire given to the students in the professional nursing issues course in the beginning of the program (see Appendix A). The Campus Learning Laboratory faculty evaluated student reading and writing skills in the first semester of nursing school (Appendices B and $\mathrm{C})$. Program exit GPA was also obtained from student academic records.

The Campus Learning Laboratory faculty utilized the "Reading and Study Skills Inventory" developed by Sherrie Nist and William Diehl in the 1985 edition of their textbook entitled Developing Textbook Thinking. This reading tool has three assessment areas: 1) to explore the student's knowledge of college study demands, 2) a short assessment to locate reading problems, and 3) the study strategies inventory yielding a quick assessment of reading retention (Nist \& Diehl, 1985). The reliability and validity of this instrument has not yet been established (Verbal Communication, Sherrie Nist, April 5, 1994).

The second instrument utilized by the Campus Learning Laboratory faculty was a form of the College Level Academic 
Skills Test (CLAST) essay for writing assessment. The CLAST is a State of Florida standardized test administered to all students entering the junior level of college of study. The assessment measure utilized was the CLAST essay used in 1990-1991. This essay is rated on a four-point rating scale with two topic areas for the student to choose from when writing the essay. The reliability and validity of this essay assessment has been well established by the Florida Department of Education (Technical Report, 1991). The reliability of this essay test is evaluated by inter-rater reliability and internal consistency. Inter-rater reliability ensures the raters adhere to established criteria for scoring the essays. "Consistency in scoring is maintained by training the raters and monitoring the scoring process and the reliability of the combined ratings is estimated by coefficient alpha" (Technical Report, 1991, p. 16). Monitoring scoring occurs through mechanisms to ensure inter-rater reliability. The data revealed $97 \%$ of the raters were identical or contiguous (within one point of each other) (Technical Report, 1991). Alpha ratings by topic for the essays from 1990-1991 show internal consistency reliability across topics. Topic one had an alpha coefficient of .71 in 1990 and .81 in 1991 and topic two had an alpha of .67 in 1990 and .78 in 1991 (Technical Report, 1991). In general alpha coefficients of above. 70 
are considered to be satisfactory (Polit \& Hungler, 1991; Munro \& Page, 1993). This data collection measure appears to be reliable.

The Florida Clast Technical report of 1990-1991 speaks to a test being valid for a particular purpose. Although the validity of an instrument is generally assessed in the three areas for content, construct, and criterion-related validity, this report states content validity is the only type of validity relative to the CLAST essay. "Content validity is the only important type for the CLAST because test scores are only interpreted in terms of what they indicate about student achievement of designated performance objectives: (Technical Report, 1991, p. 21). The CLAST does not measure a psychological characteristic so they do not measure construct validity nor does this test predict performance; therefore criterion related validity is not seen as relevant (Technical Report, 1991).

Data Collection Procedure

The data was collected over a four-semester period with the demographics and reading and writing assessments done on entry into the program in the first semester of junior year. Although CLAST writing assessment occurs prior to student admission another version of the CLAST essay was administered by the writing lab for assessment after program 
entry. The program exit GPA was obtained upon program completion with the consent of the selected BSN program. Participant confidentiality was maintained by data coding.

\section{Data Analysis}

"Direct causal effects are estimated by the magnitude of partial regression coefficients. Indirect causal effects are estimated by the magnitude of the sum of products of causal effects through intervening variables" (Wolfe, p. 386). In this way path analysis allows the investigator to unravel the direct causal effects, indirect causal effects and the noncausal components through the use of regression coefficients (Munro \& Page, 1993). Multiple regressions noted the significant effects of each variable.

Multiple regressions were calculated using as dependent variables or criterion variables each of the three endogenous variables displayed in the model: program exit grade point average, reading score, and writing score. In each regression the dependent or criterion variable and variables specified as being related to this variable will create the predictor variable set. Path coefficients were obtained with significance for retaining a path coefficient at $p<.05$. Next the direct and indirect effects were explored, the pathways with no statistical significance, were eliminated, the model was trimmed. The analysis was 
then recalculated with only the retained variables. Path coefficient changes produces the final preliminary model.

Data was also obtained on frequency, mean, standard deviation, and range of all scores for each of the variables of the model as well as correlational coefficients.

\section{Methodological Assumptions}

It was assumed for the purposes of this study:

1. The students who participated in this study were representative of the target population for which this study was designed.

2. Path analysis enables measurement of the direct and indirect effects that one variable has on another variable.

3. All relevant variables are included in the model.

4. There is a one way causal direction in this model testing the use of Bloom's Mastery Model concepts.

\section{Methodological Limitations}

Although previous limitations have been discussed, it was noted the following conditions may influence the results of the study. Therefore, caution should be used when generalizing the results or in drawing inferences from these findings.

1. The model for the study has a causal flow which is 
unidirectional.

2. Recursive path analysis is always dependent upon inclusion of all relevant variables, the use of measures that are reliable, and the necessity of controlling for residuals from different equations which might be intercorrelated. The reading instrument has no established reliability.

3. Nursing knowledge obtained from the five semesters in the nursing program was not addressed. It was assumed to be an exogenous variable, but not a concept of Bloom's Mastery Model; therefore, not under consideration at this time.

4. As an Ex Post Facto design, this investigation limited in its ability to actively manipulate the independent variables, randomly assign participants, and the contingency that there may be misinterpretation of results.

\section{Human Assurance}

The permission to utilize the demographic data will be noted by the student's willingness to return the questionnaire. Permission to obtain the students' exit grade point average by a non-identifying coding method for the explicitly use of this educational research was obtained from the Dean of the School of Nursing. 


\section{$\underline{\text { RESULTS }}$}

The use of recursive path analysis allowed for the investigation of the path of causal relationships existing among a set of variables occurring in a specified sample of an upper division multicultural baccalaureate nursing program. The causal model included mediator variables of reading and writing scores; predictor variables of entry characteristics; and the outcome variable of program exit grade point average. The data were analyzed to test the following research questions at the $p<.05$ level of significance:

1. What is the relationship between learner entry characteristics and reading and writing scores?

2. What is the relationship between reading and writing scores and program exit grade point average?

3. What is the relationship between learner entry characteristics and program exit grade point average?

Analysis of data was conducted at the University of Oklahoma, Oklahoma City, Oklahoma using the computer resources of the college of Nursing (see Appendices D and E) . Both descriptive and inferential statistical procedures 
were applied to the data using the Statistical Package for the Social Sciences (SPSS) (Norusis, 1988). Data was obtained for correlational coefficients of the model as well as frequencies, means, standard deviations, and range of all scores for each of the model variables. Data for partial regression coefficients was obtained from the standardized regression coefficient or Beta. As a partial regression coefficient, it is the measure of the relationship between the independent and dependent variable with the influence of the other independent variables being held constant (Munro \& Page, 1993). In this analysis with only one independent variable regressed at a time, the partial regression coefficient or path coefficient is simply a measure of correlation between two variables.

Description of Sample

The sample consisted of 128 females and 15 males. A summary of selected characteristics of the sample participants is displayed in Table 3. Specific characteristics from this table are discussed in detail. 
Table 3

Entry Characteristics

Age

$$
\begin{aligned}
& 19-12 \\
& 21-23 \\
& 24-27 \\
& 28-30 \\
& 31-34 \\
& 35-40 \\
& \hline \text { Total }
\end{aligned}
$$

$\begin{array}{r}35 \\ 43 \\ 31 \\ 12 \\ 5 \\ 10 \\ \hline 136\end{array}$

26.3

29.3

23.3

23.3

8.3

$\frac{7.5}{98.5}$

Gender

Male

Female

15

128

10.5

Total

$\frac{128}{143}$

89.5

Ethnicity

Bahamas

Cuba

Haiti

Jamaica

Puerto Rico

United States

Other

Total

\begin{tabular}{rr}
4 & 2.8 \\
20 & 14.0 \\
15 & 10.5 \\
9 & 5.6 \\
5 & 3.5 \\
84 & 59.4 \\
6 & $\quad 4.2$ \\
\hline 143 & 100.0
\end{tabular}

Transfer

MDCC

University Transfer

84

58.7

Native

16

11.2

15

10.5

21

14.7

Other

Total

$\frac{5}{141}$

$\frac{3.5}{100.0}$

English As A second Language

Spanish

38

25.9

French

English Only

Total

24

$\frac{81}{143}$

16.8

$\frac{57.3}{100.0}$

Has Not Graduated With Entry Class

Graduated

119

83.2

18

Did Not Graduate Total

$\frac{6}{143}$

12.6

$\frac{4.2}{100.0}$ 
The mean age for the sample was 24.7 years with the minimum age of 19 noted and the maximum age of 50 years noted. These age ranges are seen in Table 4. 
Table 4

Age at Program Admission

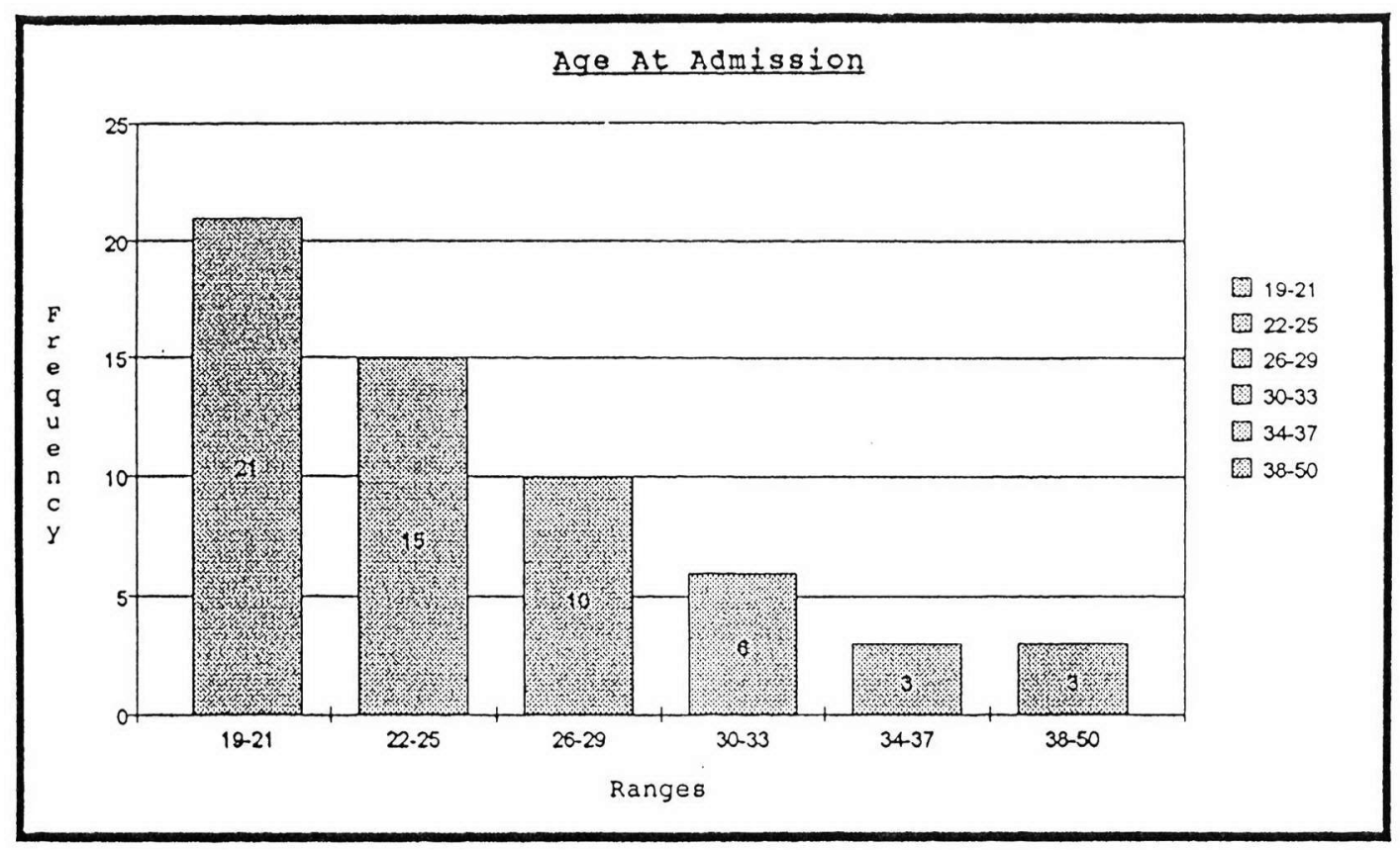


Ethnicity for this sample was quite varied. The majority of the sample selected the United Sates as their ethnic background with 84 participants or $58.7 \%$ of the sample from the United States. The findings of the ethnic mix of this sample are presented in Table 5. The ethnic spectrum presented in Table 5 is representative of the usual student ethnicity seen in Southeastern Florida community colleges and universities.

Table 5

Ethnicity

ETHNICITY FREQUENCY PERCENT

Bahamas

4

2.4

Cuba

20

14.0

Haiti

15

10.5

Jamaica

8

5.6

Puerto Rico

5

3.5

United States

85

59.4

Other

$\frac{6}{143}$

$\frac{4.2}{100.0}$

This upper division school admits transfer students from area universities and community colleges. Miami-Dade Community College (MDCC) is the institution most frequency 
transferred from in this sample with $58.7 \%$ or 84 participants from MDCC. Other sample participants were from Broward Community College $(\mathrm{BCC})$, native students (Florida International University under classmen), and transfer students from other universities. The transfer institution findings are presented in Table 6 .

The participants entering obtained various degrees before entry into this upper division program. The degree most frequently obtained before entry was an associate of arts degree (A.A.) with $75.9 \%$ of the participants obtaining the associate degree. 
Table 6

Transfer Institution

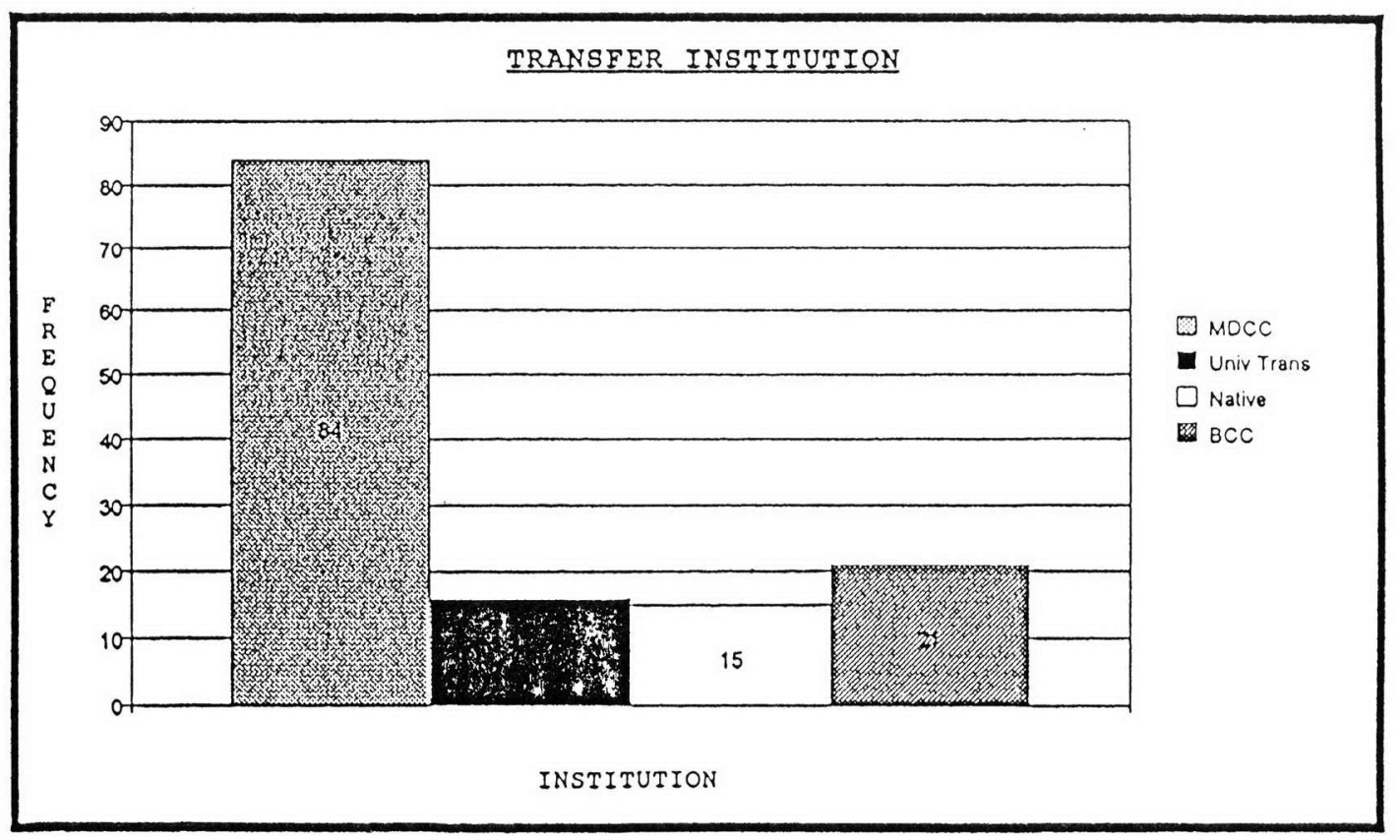


English as a Second Language (ESL) was a varied finding for this sample (Table 7). The language other than English frequently spoken was Spanish with $25.9 \%$ or 38 participants speaking Spanish. French was spoken by $15.8 \%$ or 24 participants in this sample. 
Table 7

Participant's Language

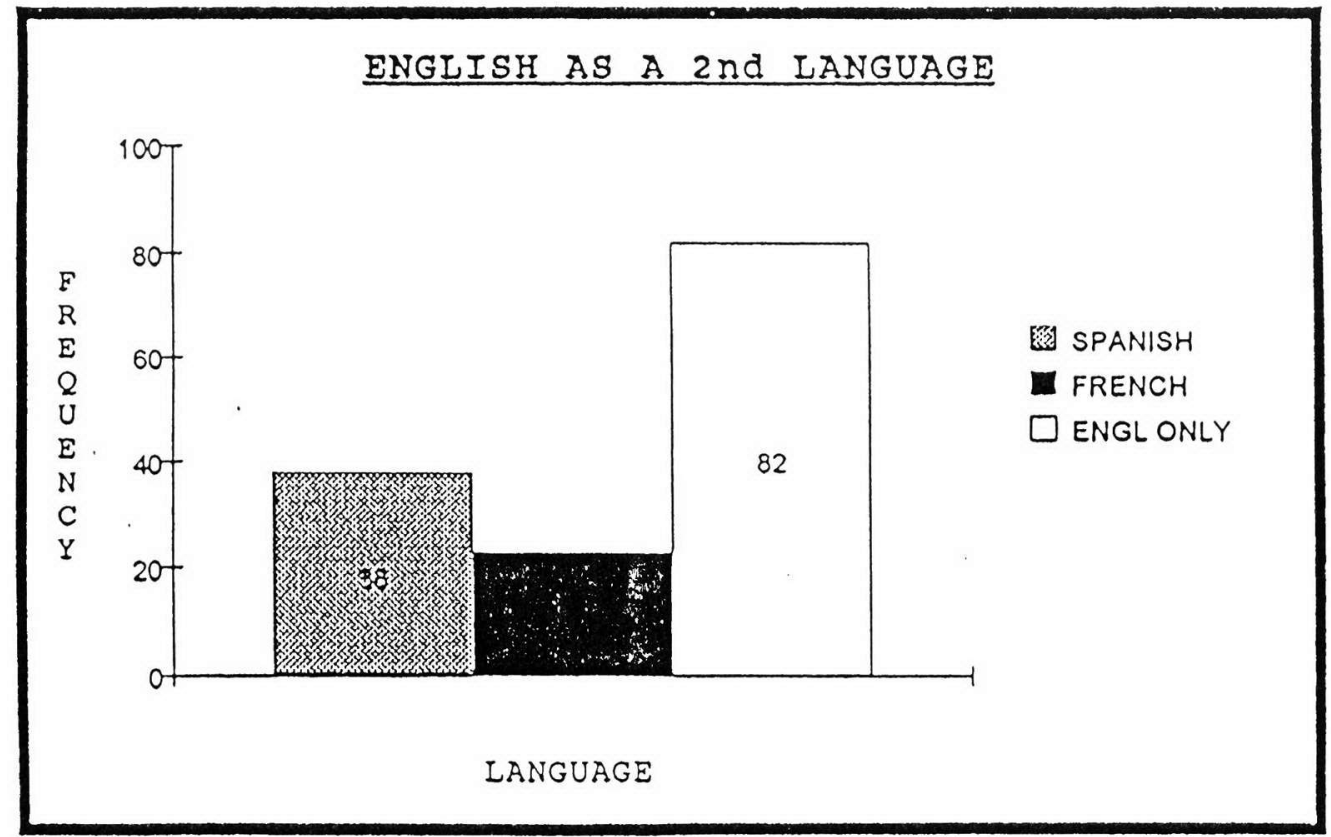


The mean entry grade point average for this sample was a 2.91 with a range of 1.60 , a minimum grade point average of 2.23 and a maximum grade point average of 3.83 . The standard deviation was .38 . There were eight missing cases in entry grade point average data. Table 8 summarizes entry grade point average findings. The mean entry GPA is relatively close to the norm for entry GPAs in area upper division nursing programs. Table 8 presents an almost trimodal distribution of entry GPA. The group in the upper range had an entry GPA clustering around 3.6, a second group had a clustering of GPA around 3.3 and the third group and majority of the students had a 2.9 entry GPA. 
Table 8

Program Entry Grade Point Average

$\begin{array}{lrlrll}\text { Mean } & 2.913 & \text { Std Err } & .040 & \text { Median } & 2.90 \\ \text { Mode } & 3.000 & \text { Std Dev } & .383 & \text { Variance } & .214 \\ \text { Maximum } & 3.830 & \text { Range } & 1.600 & \text { Minimum } & 2.230\end{array}$

PROGRAM ENTRY GPA

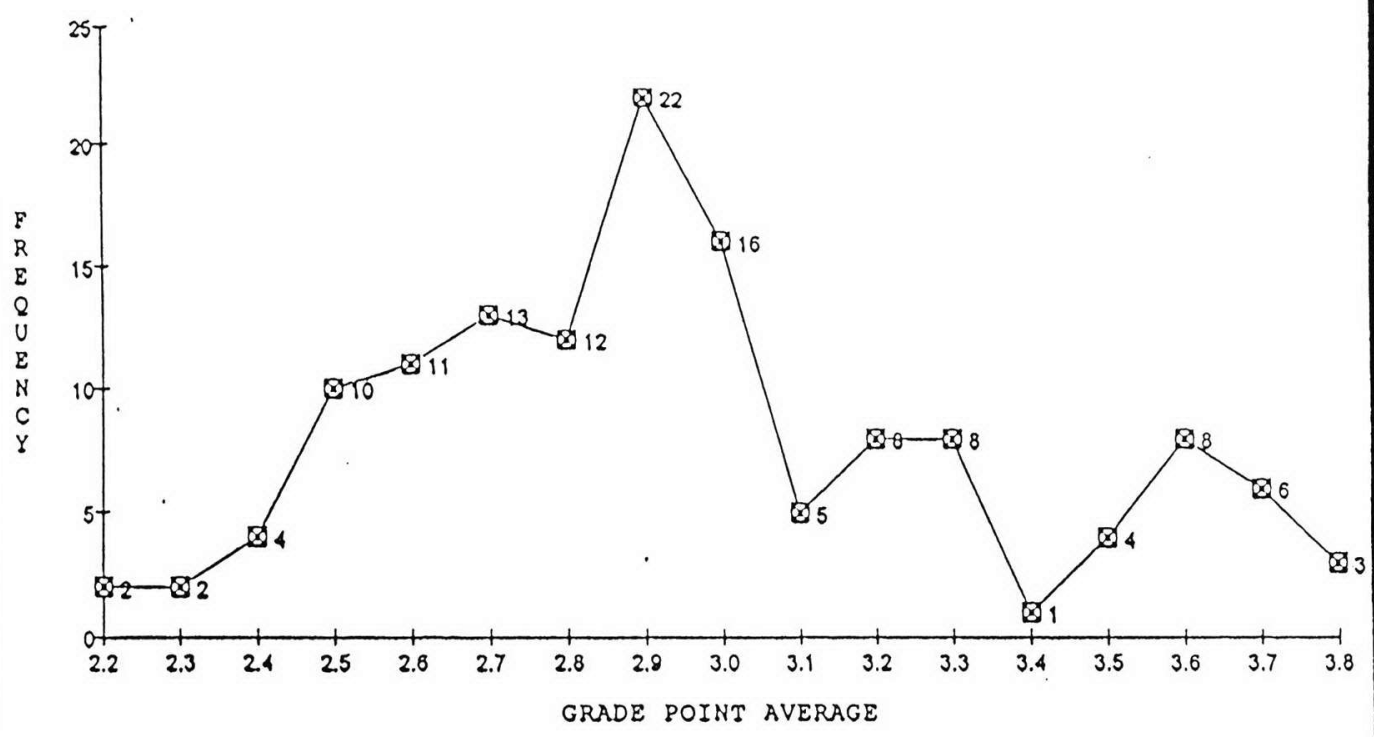


Race was obtained in the demographic data profile of entry characteristics of the participants. Race and ethnicity are not included in the model for data analysis because race, ethnicity, and ESL were nominal data sets and somewhat repetitive variables. The point of interest in this model of these variables could be best analyzed by entering the ESL findings into the model testing; therefore, only ESL as a nominal data set was analyzed in the regressions. For the purpose of delineating diversity the participants race was analyzed for this sample description. These findings revealed Asian .7\%, Black 31.5\%, Hispanic 21. $\%$, Caucasian $44.8 \%$, and other $1.4 \%$

The mean exit GPA was 3.18 . the percentage of subjects who did not graduate with their entry class due to course failures was $16.8 \%$. Of this group, $12.6 \%$ graduated with the next class and $4.2 \%$ did not graduate from the program due to repeated course failure or a GPA below program requirements.

Reading scores for all participants were obtained from the study skills inventory section of the reading assessment. These were the scores utilized by the Learning Laboratory faculty to determine reading level and could range from Level 1 to Level 18. The reading scores' statistics are presented in Table 9. A fifteen level span occurred in the range of reading levels of participants. Seventeen was the maximum reading level obtained and two was 
the minimum reading level obtained. This mean reading level is low for the college student required to read technical textbooks.

Table 9

Reading Scores

\begin{tabular}{lrlrlr}
\hline Mean & 8.554 & Std Err & .244 & Median & 9.000 \\
Mode & 9.000 & Std Dev & 2.875 & Variance & 8.263 \\
Maximum & 17.000 & Range & 15.000 & Minimum & 2.000 \\
\hline
\end{tabular}

The writing score essay results for this sample were obtained utilizing the four point essay rating scale developed by the Florida Department of Education Clast exam. This was the second writing assessment for this sample. The CLAST essay is required before admission, however, a version of the CLAST essay was administered by the writing laboratory for further writing assessment following program admission. Table 10 presents these findings. The mean writing score for this sample was 2.39 with a mode of 3.00 . Writing scores revealed $50.7 \%$ of sample participants scored below a score of 2 on this assessment and were considered to need Learning Laboratory referral for assistance with their writing skills. 
Table 10

Writing Scores

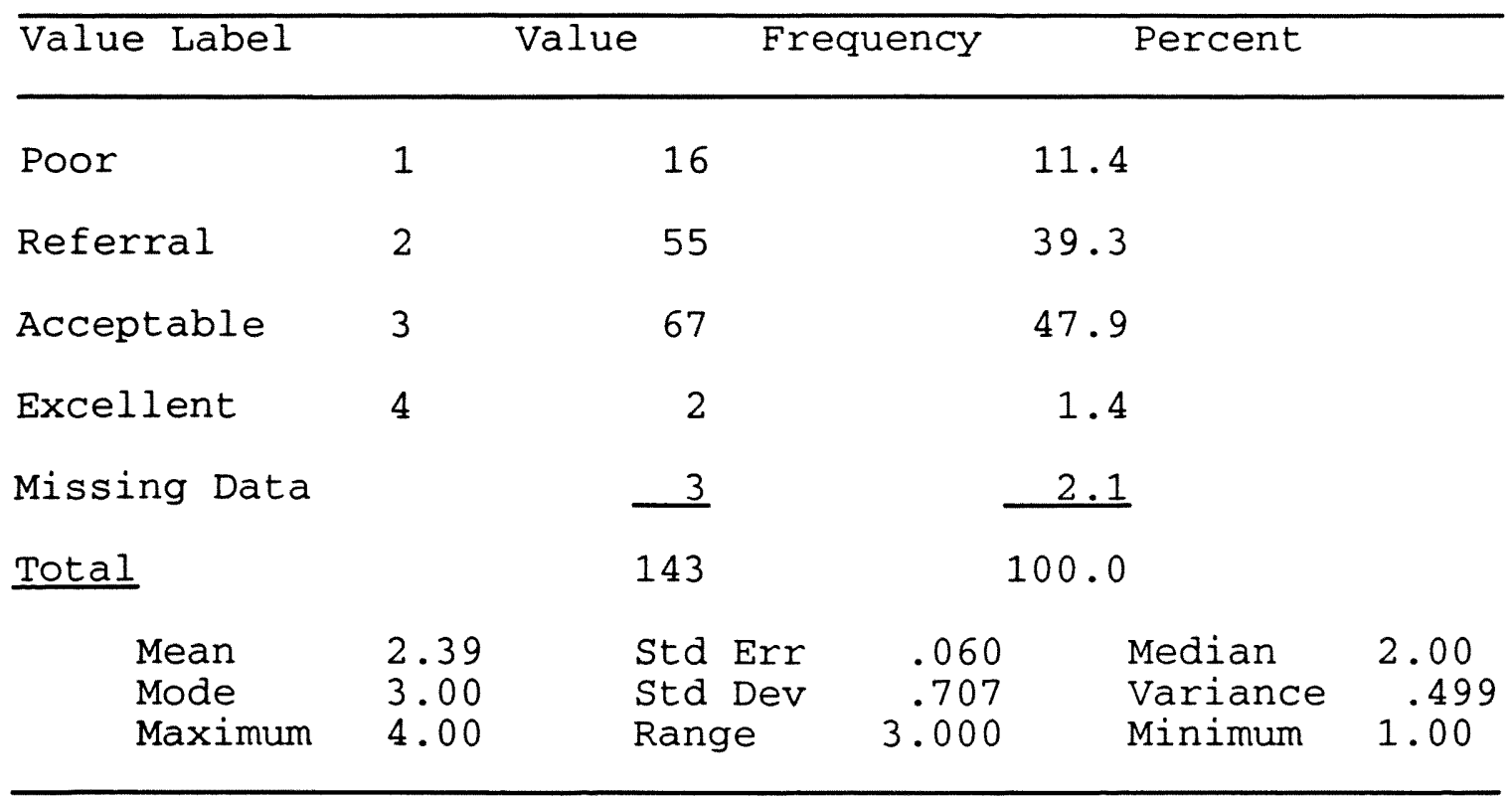

Correlations Discussion

In order to explore all possible relationships among the variables, a correlation matrix was produced. Correlation matrices to test for multicollinearity of the theoretical model variables were done. Pearson correlation coefficients for all pairs of variables are presented in Table 11. Significant pairs were starred in this table. However, in assessing the "true meaningfulness" of the coefficient the preferred method is determination of how much variance the two variables share (Munro, 1991). Munro (1991, p. 149) describes the strength of the relationship in terms of the following scale: 


$$
\begin{array}{ll}
0.00-0.25 & \text { Very Low } \\
0.26-0.49 & \text { Low } \\
0.50-0.60 & \text { Moderate } \\
0.70-0.89 & \text { High } \\
0.90-1.00 & \text { Very High }
\end{array}
$$

Utilizing this table there were no pairs of variables with moderate to high percentages of shared variance and no pairs of variables were in the moderate or low categories. Two pairs of variables were in the very low category. Writing score and entry GPA had a shared association of (.20) and entry GPA and exit GPA had a shared association of (.23). For all pairs of variables correlated, only two pairs of variables demonstrated a very low strength of relationship; all other pairs demonstrated no meaningful relationship. There was no correlation data supporting multicollinearity. 
TABLE 11

CORRELATION COEFFICIENTS FOR ALL PAIRS OF VARIABLES ( $N=143$ )

\begin{tabular}{|c|c|c|c|c|c|c|c|c|c|}
\hline VARIABLES & 1 & 2 & 3 & 4 & 5 & 6 & 7 & 8 & 9 \\
\hline 1. AGE & 1.00 & & & & & & & & \\
\hline 2. GENDER & $0.17^{\star}$ & 1.00 & & & & & & & \\
\hline Female $=0$ & & & & & & & & & \\
\hline Male $=1$ & & & & & & & & & \\
\hline 3. TRANSFER & $-0.07 \star$ & 0.02 & 1.00 & & & & & & \\
\hline Comm Coll=0 & & & & & & & & & \\
\hline University=1 & & & & & & & & & \\
\hline 4. SPANISH & $-0.16^{\star}$ & $0.07 \star$ & $-0.10^{\star}$ & 1.00 & & & & & \\
\hline 5. FRENCH & $0.20 \star$ & -0.03 & $-0.08 *$ & $-0.25^{\star}$ & 1.00 & & & & \\
\hline 6. ENTRY GPA & -0.02 & $0.10^{\star}$ & $0.31^{\star}$ & $0.11^{\star}$ & $-0.09 \star$ & 1.00 & & & \\
\hline 7. READING SCORE & 0.01 & $0.06^{\star}$ & $0.35^{\star}$ & $0.30 \star$ & -0.04 & $0.32 \star$ & 1.00 & & \\
\hline 8. WRITING SCORE & $-0.09 *$ & -0.02 & $0.31 \star$ & 0.02 & $-0.16^{\star}$ & $0.45^{\star}$ & $0.15^{\star}$ & 1.00 & \\
\hline 9. EXIT GPA & -0.00 & 0.04 & $0.24^{\star}$ & 0.03 & $-0.34^{\star}$ & $0.48^{\star}$ & $0.32 \star$ & $0.32 \star$ & 1.00 \\
\hline
\end{tabular}

Note. All significant levels are based on a two-tailed test.

${ }^{\star} \mathrm{p}<.05$ 
Selected Path Presentation

Path analysis and causal interpretation is a method of viewing the logical consequences of two assumptions, causal order among a set of variables and (2) the relationships among these variables are causally closed (Blalock, 1970). "The decision about causal ordering is an important decision in the design and analysis of cause, but it is not a statistical decision" (Munro \& Page, 1993, p. 277). This decision depends on reason, logic, and some background information about the variables (Munro \& Page, 1993) .

In analyzing the path model depicted in Figure 2, parsimony was maintained by selecting the minimum number of explanatory variables when formulating the model. Parsimony and measurement of data on an interval scale are important assumptions of path analysis. As stated previously path analysis ideally interprets interval data; however, there are real world phenomena important to outcomes which are not measured in an interval scale. This phenomena or categorical variable is measured on a nominal scale, but has an important impact on the causal relationship. To avoid overuse of nominal measures, overlapping nominal level variables were excluded from the model and only the categorical variable having the most direct impact on the outcome was included in the model. 
Utilizing this logic, race, ethnicity, and ESL were all nominal variables with overlapping data. The ESL data combines the essence of the variables ethnicity and race as they impact the participants' program outcome grade point average. It is not the participants' race which determines the program outcome nor the ethnic origin of the participant, but rather the participants' ability to conceptualize and learn the nursing process in the English language.

Coding of nominal data was done by a process known as dummy coding as outlined by Pedhazur (1982). Categorical variables requiring dummy coding were gender, transfer institution, and ESL.

The categorical variable of transfer institution was coded by comparing only those who were admitted from a community college (coded as 0 ) and those participants who were admitted from a university setting (coded as 1). The rationale for this grouping emerged from the similarity of value means for the four transfer institutions' entry grade point averages (Table 12). Grouping by community college or university transfer occurred because of the small sample sizes and similarity of grade point average means.

The same rationale was utilized in the decision to omit the nominal variable of the participant's previous degrees. There were 108 associate degrees, 9 bachelor 
degrees, and 24 participants with no degree. The small sample sizes and similarity of this categorical variable, previous degree, to the variable transfer institution was the rationale for omission of this nominal variable from the path analysis.

Table 12

Transfer Institution's Mean Entry GPA

\begin{tabular}{llll}
\hline Institution & Mean & Std Dev & Case \\
\hline Miami-Dade Community College & 2.87 & .3732 & 77 \\
Broward Community College & 2.88 & .3448 & $\underline{20}$ \\
Total & & & 97 \\
University Transfer & 3.09 & .4079 & 16 \\
Native & 3.23 & .2711 & $\underline{15}$ \\
Total & & & 31 \\
\end{tabular}

Again, parsimony of variables is encouraged in path analysis and the data were overlapping between transfer institution and previous degree.

ESL was the final categorical variable coded by the use of dummy coding. The coding yielded two dummy variables for three categories. Spanish was coded as one and non-French was coded as zero. The language of French noted in investigation was actually Creole, a form of French and the primary language of the Haitian culture. Those who spoke 
only English were given a zero in both categories.

The symbol for path coefficients is a $\mathrm{P}$ with two

subscripts. The first subscript indicates the dependent variable and the second subscript the independent variable (see Figure 2).

The untested path model began with nine variables. The variables were: age, gender, transfer institution, Spanish, French, entry GPA, reading score, writing score, and program exit GPA. The path analyses were performed by regressing exit GPA on all variables; regressing exit GPA on the entry characteristics: age, gender, transfer institution, Spanish, French, and entry GPA; and by regressing exit GPA on the basic skills of reading and writing.

The second phase involved regressing reading score on all entry characteristics and finally regressing writing score on all entry characteristics. The path for model analyses described above are seen in Figure 3.

Figure 3, depicts the standardized regression coefficients or Beta weights obtained when dependent variables were regressed upon the selected independent variables. Statistical significance at the $p<0.05$ level as a criterion for deleting paths was utilized in this emerging model (Munro \& Page, 1993; Pedhazur, 1982; Wolfe, 1985).

Following deletion of paths the model was trimmed by rerunning the analyses with only the retained variables. 
BLOOM'S LEARNING MODEL
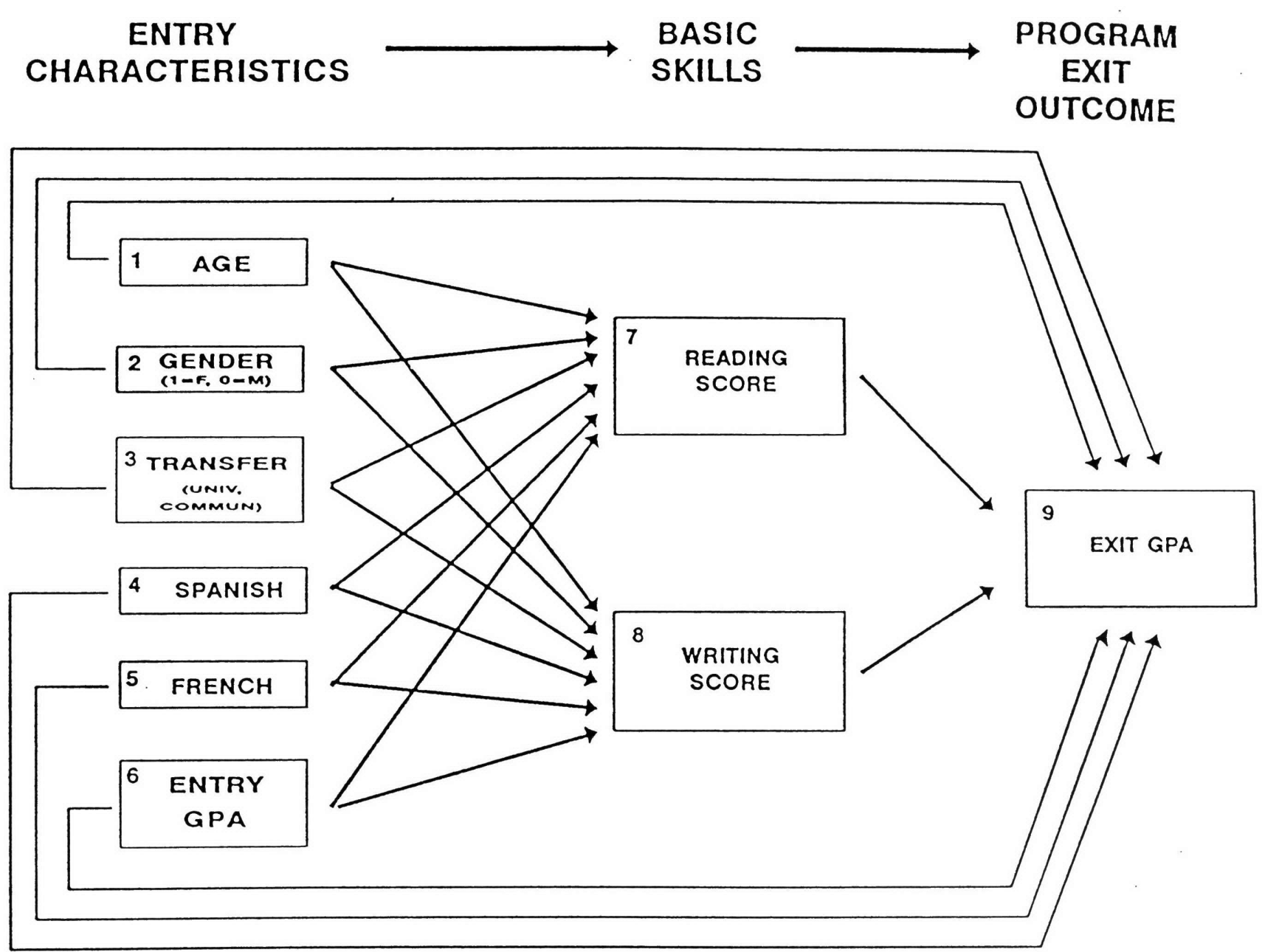

FIGURE 2. UNTESTED MODEL OF PROGRAM EXIT OUTCOME 
BLOOM'S LEARNING MODEL
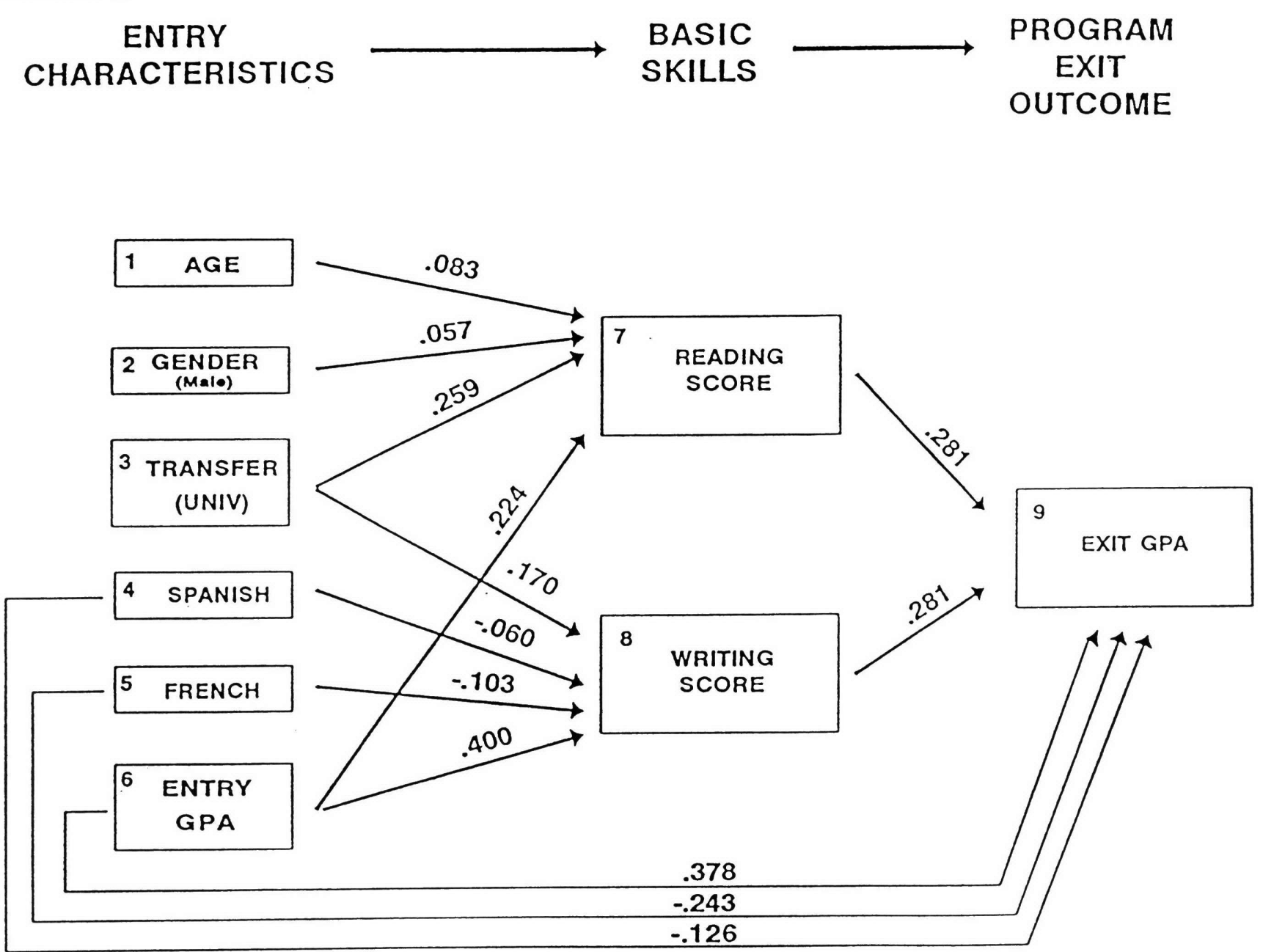

FIGURE 3. PATHS OF THE EMERGING MODEL 
The new regressions are depicted in Figure 4. Note, recalculated regressions only deleted one path from the model. The deleted path was between the variables Spanish and writing skill score. This path coefficient in the trimmed model was -.03884 and was deleted at the $\mathrm{p}<.05$ level of significance. The path between Spanish and exit GPA remained significant and the two variables were inversely related. The student for whom Spanish was the first language had a lower exit GPA. Spanish had a direct effect on exit GPA and no longer displayed an indirect effect via the mediating variable writing score. Writing score was not a mediating variable for Spanish. In order for this relationship to be maintained there must be a significant path between Spanish and writing score. This is known as the mediator effect and occurred between French and writing score. Mediator variables influence the relationship between the predictor variable and the outcome variable and may increase or suppress the relationship between the predictor and outcome variables (See Figure 4). 
BLOOM'S LEARNING MODEL
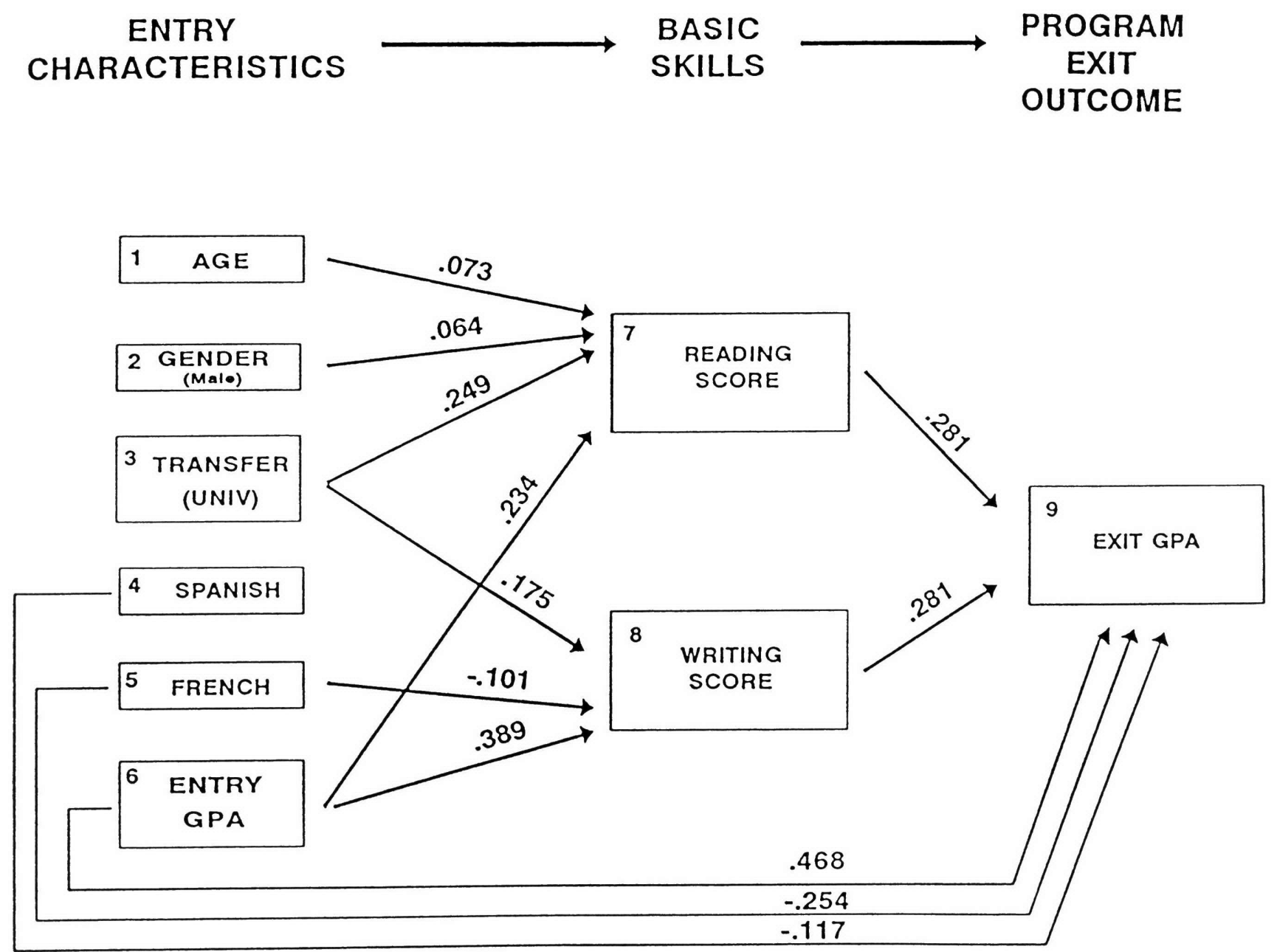

FIGURE 4. TRIMMED MODEL OF PROGRAM EXIT OUTCOME 
In Table 13, the decomposition of the correlation between variables is displayed. The influence of variables directly in the path of other variables is termed "direct effects" and represents the covariation between two variables which is causal or "genuine" (Nie, 1975). The indirect influence of variables within a path (indirect effects) as well as the total causal effect are displayed to allow calculation of causal and noncausal effects (Munro \& Page, 1993). "If there is a difference between the total causal effect and the original correlation, this indicates that a portion of the original correlation was noncausal or spurious" (Munro \& Page, 1993, p. 281). From this table noncausal covariation or spurious findings were seen between the following variables: entry GPA and reading score, French and writing score, entry GPA and writing score, writing score and exit GPA, entry GPA and exit GPA, and French and exit GPA. Spurious findings indicate the proportion of the original correlation which was noncausal. Spurious effects refer to the remainder of the correlation between two variables due to the fact that they share a common cause, actually another variable. More specifically, "the direct effect of variable 2 on variable 3 is equal to $\mathrm{p} 23$, due to the fact they share a common cause--namely, variable 1" (Pedhazzur, 1982, p. 589). In Table 13 noncausal correlations can only be determined in the paths where the indirect effects have been 
determined.

This table also provides covariations which were decomposed to determine what percentage of the causal relationship occurs due to an intervening variable and are represented by the indirect effects. For example, entry GPA has a direct effect on reading score and a direct effect on exit GPA. Entry GPA has an indirect effect on exit GPA and is mediated by reading score and writing score.

Indirect effects were calculated by determining the two ways a variable may influence another variable and multiplying these path coefficients to obtain the indirect effect. The total causal effect is the sum of the direct and indirect effects. The non-causal correlation or covariation or spurious findings is the total causal influence minus the direct effect.

In reviewing Table 13, the total causal effect coefficients for entry GPA are .365, .520, and .577 . Entry GPA has the largest effect on exit GPA, followed by writing, and the least total causal effect reading. The total causal effect of French as a first language -.007 and -.282 . It may be concluded French has its greatest total causal effect $(-.282)$ on exit GPA. However, the total causal effect of French on writing is relatively small (-.007) and not significant. This variable maintained an inverse relationship with the variable French as a first language 
and exit GPA. Total causal effects impacting exit GPA were writing score (.462), entry GPA (.520), and French (-.282). Of the three variables affecting exit GPA, entry GPA had the largest total effect, followed by writing score and then French as a first language. French maintained and the inverse relationship with exit GPA in the total causal effects; therefore, students speaking this language demonstrated decreased exit GPAs. Direct and indirect effects can be compared in the same manner as above (See Table 13). 
Table 13

Direct, Indirect and Total Causal Effects

\begin{tabular}{|c|c|c|c|c|}
\hline & $\begin{array}{l}\text { Direct } \\
\text { Effect }\end{array}$ & $\begin{array}{l}\text { Indirect } \\
\text { Effect }\end{array}$ & $\begin{array}{l}\text { Total Causal } \\
\text { Effect }\end{array}$ & $\begin{array}{l}\text { Noncausal } \\
\text { Correlation }\end{array}$ \\
\hline \multicolumn{5}{|l|}{ Paths } \\
\hline Age to Reading & .073 & & .073 & 0 \\
\hline $\begin{array}{r}\text { Gender (Male) } \\
\text { to Reading }\end{array}$ & .064 & & .064 & 0 \\
\hline $\begin{array}{l}\text { University } \\
\text { to Reading }\end{array}$ & .248 & & .248 & 0 \\
\hline $\begin{array}{l}\text { University } \\
\text { to Writing }\end{array}$ & .175 & & .175 & 0 \\
\hline $\begin{array}{l}\text { Entry GPA } \\
\text { to Reading }\end{array}$ & .234 & .131 & .365 & 0 \\
\hline $\begin{array}{l}\text { French } \\
\text { to writing }\end{array}$ & -.101 & -.072 & -.007 & .094 \\
\hline $\begin{array}{l}\text { Entry GPA } \\
\text { to Writing }\end{array}$ & .388 & .131 & .520 & -.131 \\
\hline $\begin{array}{l}\text { Writing } \\
\text { to Exit GPA }\end{array}$ & .280 & .181 & .462 & .181 \\
\hline $\begin{array}{l}\text { Reading } \\
\text { to Exit GPA }\end{array}$ & .280 & - & .280 & 0 \\
\hline $\begin{array}{l}\text { Entry GPA } \\
\text { to Exit GPA }\end{array}$ & .468 & .109 & .577 & .109 \\
\hline $\begin{array}{l}\text { French } \\
\text { to Exit GPA }\end{array}$ & -.253 & -.028 & -.282 & .028 \\
\hline $\begin{array}{l}\text { Spanish } \\
\text { to Exit GPA }\end{array}$ & -.117 & 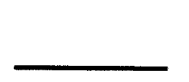 & -.117 & 0 \\
\hline
\end{tabular}




\section{Presentation of Findings}

Research Question 1

Research question 1 explored, what is the relationship between learner entry characteristics and reading and writing scores? There is a statistically significant relationship between learner entry characteristics and reading and writing scores. A significant relationship was partially supported (see Figure 5).

Significant path coefficients were noted on the paths of entry GPA, age, male gender, and transfer from a university to reading score. Entry GPA and university transfer had direct effects on reading score. University transfer had the largest direct effect (.248) on reading score. Entry GPA followed university transfer and had the second largest direct effect $(.234)$ on reading score. The direct effects of age (.073) and male gender (.064) were relatively small although significant at the $\mathrm{p}<.05$ level. The university transfer student with a high entry GPA scored higher on the reading assessment and the older, male, university transfer student with a high entry GPA obtained the highest score on the reading assessment.

A significant relationship was noted between writing score and university transfer, entry GPA, and French in this upper division program. Entry GPA (.388) had the largest direct effect on writing score. University transfer (.175) 
had the second largest direct effect on writing score French was the final variable with a direct effect on writing score. The direct effect was -.101, although small the inverse association indicates students speaking French, specifically Creole, had lower writing scores than did other sample participants. Finally, the university transfer student with a high entry GPA did the best on writing assessment (see Figure 5). 


\section{BLOOM'S LEARNING MODEL}

\section{ENTRY CHARACTERISTICS \\ BASIC \\ SKILLS}

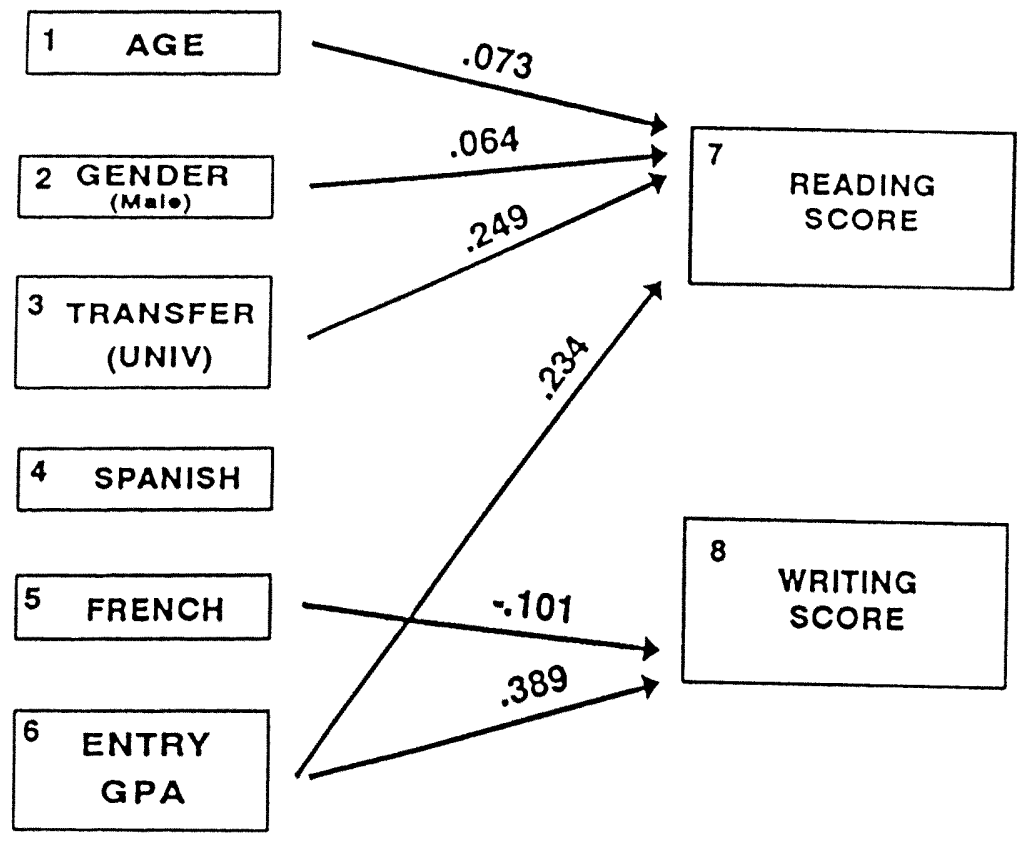

Figure 5. Research Question 1. Findings $(p<.05)$ 
Research Question Two

Research question two explored the relationship between reading and writing scores and program exit grade point average? A significant relationship occurred between the dependent and independent variables. The path coefficients from reading score and writing score to program exit GPA demonstrated the direct effect of these basis skills variables on the outcome variable exit GPA (see Figure 6). Specifically, reading (.280) and writing scores $(.280)$ each had the same direct effects on exit GPA and the higher the student's reading and writing assessment scores the higher the student's exit GPA. 

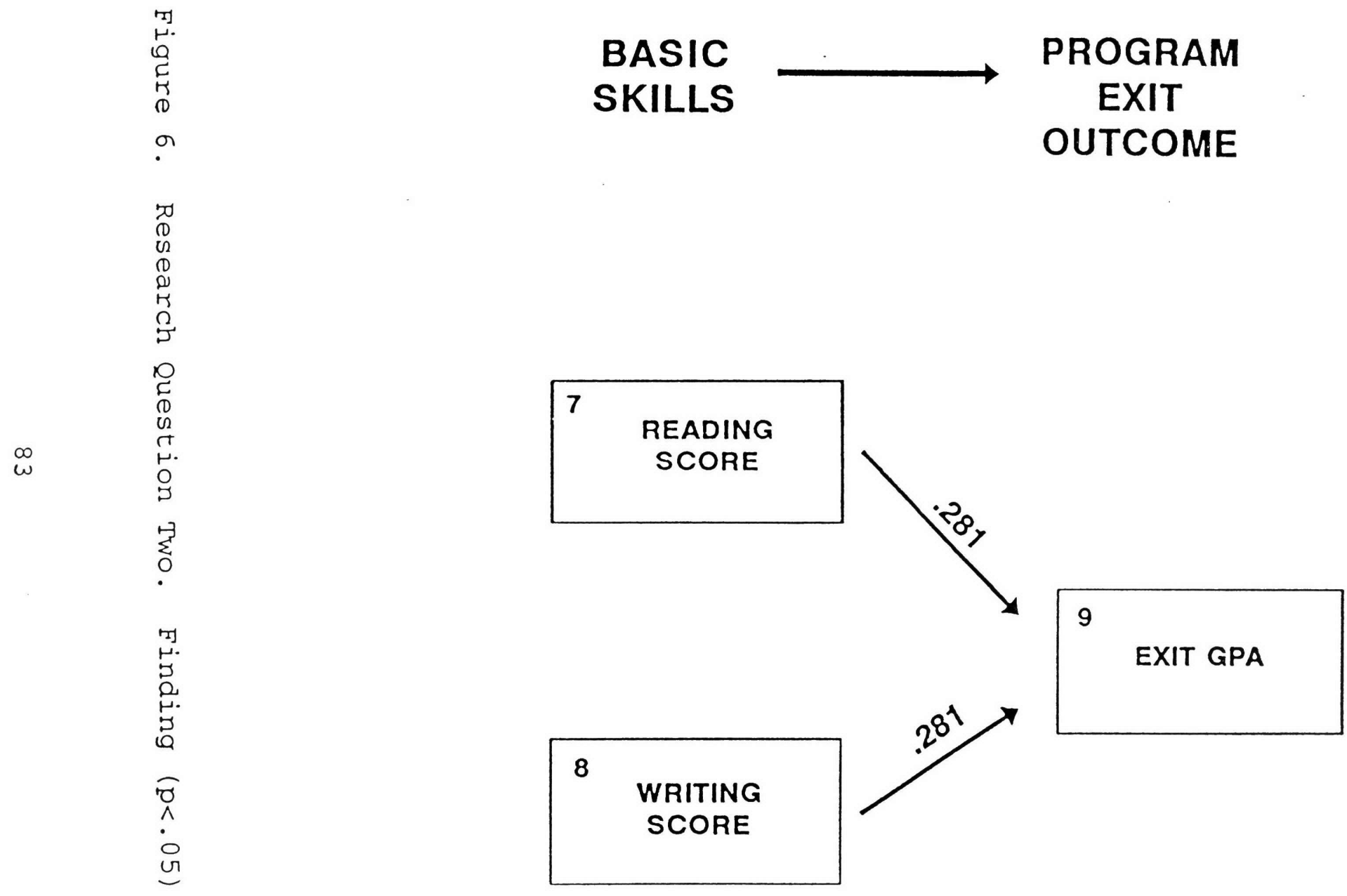


\section{Research Question Three}

Research question three explored the relationship between learner entry characteristics and program exit grade point average? A significant association was supported between program entry grade point average, French, and Spanish and exit grade point average. Entry GPA was the strongest predictor of exit GPA. Entry GPA (.468) had the largest direct effects on exit GPA; therefore, the higher the student's entry GPA; the higher the student's exit GPA. It is also noted there was a inverse association between Spanish and French as a first language and program exit grade point average (see Figure 7). French as a first language $(-.253)$ had greater direct effects on exit GPA than did Spanish (-.117). If French or Spanish were the student's first language then the student demonstrated a lower exit GPA. 


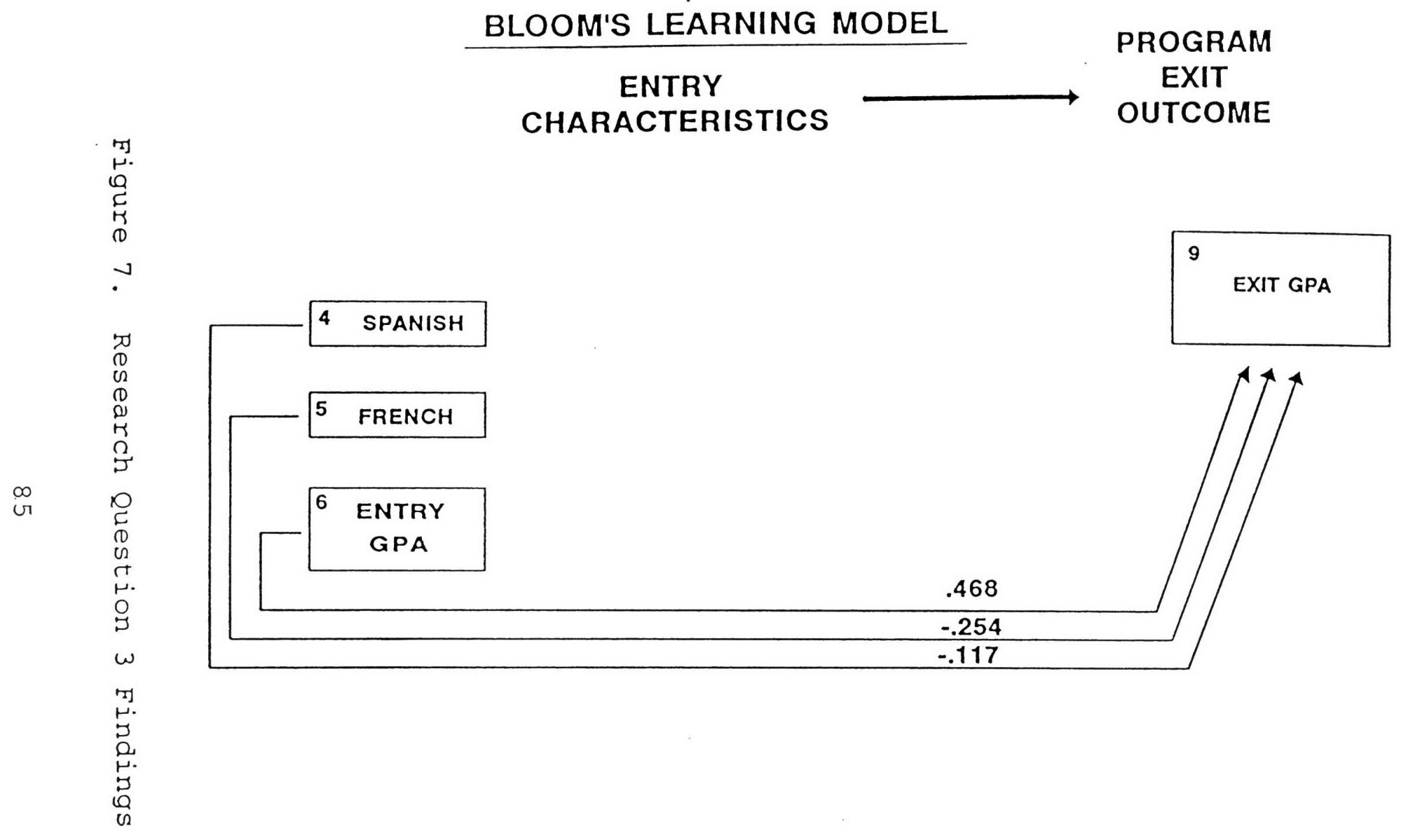




\section{Summary of Findings}

A path analysis was performed to explore the three research questions which were: the relationship of entry characteristics to the program exit outcome, entry characteristics relationship to reading and writing scores, and reading and writing scores relationship to program exit outcome. French, and entry GPA were entry characteristics which had significant paths to both program exit outcome and writing score. These paths, mediated by writing score, had an indirect effect on exit GPA as well as having direct effects on exit GPA. French as a first language had an inverse association with both variables, exit GPA and writing score.

Paths with significant coefficients relating directly to exit GPA were reading, writing, entry GPA, French, and Spanish. Spanish and French were inversely correlated with exit GPA.

Paths with significant coefficients relating to reading score were age, male gender, entry GPA, and university transfer to this program. These variables were mediated by reading in their relationship to exit GPA and exit GPA shared direct effects as well as indirect effects with these variables.

Paths with significant coefficients relating to writing score were entry GPA, university transfer, and French. 
French had an inverse association with writing score.

The standardized regression coefficients represent the path coefficients or the direct effects of two variables in this path. The indirect effects were calculated by multiplying the path coefficients of the two other variables seen as indirectly in this path. By adding the indirect and direct effects the total causal effect was obtained. Calculation of the noncausal component or covariation was obtained by the difference between the total causal effect and the original correlation. Spurious findings were noted as well as indirect effects and total causal effects.

The correlation matrix was recreated by imputing only the significant variables of the trimmed models (Table 14). This matrix revealed university transfer, French, entry GPA, reading score, and writing score were each significantly correlated with program exit GPA at $\mathrm{p}<.05$ level. However, utilizing the strength of relationship scale noted previously there were no pairs with moderate to high percentages of shared variance, specifically a correlation ranging from 0.50 to 1.00 . All of these variables with the exception of university transfer had direct effects on exit GPA in the model and all of these variables had significant shared variance with exit GPA in the original correlation matrix. University transfer had a significant indirect effect on exit GPA mediated by reading score, but no direct 
effect on exit GPA.

In Table 14, multicollinearity was relatively low, concluding that most of the variables did have direct effects on the dependent variable and that the correlation of each independent variables with the dependent variable is not due to the operation of correlated causes, but rather due to the model investigated (Pedhazur, 1982). 
TABLE 14

CORRELATIONS OF TRIMMED MODEL

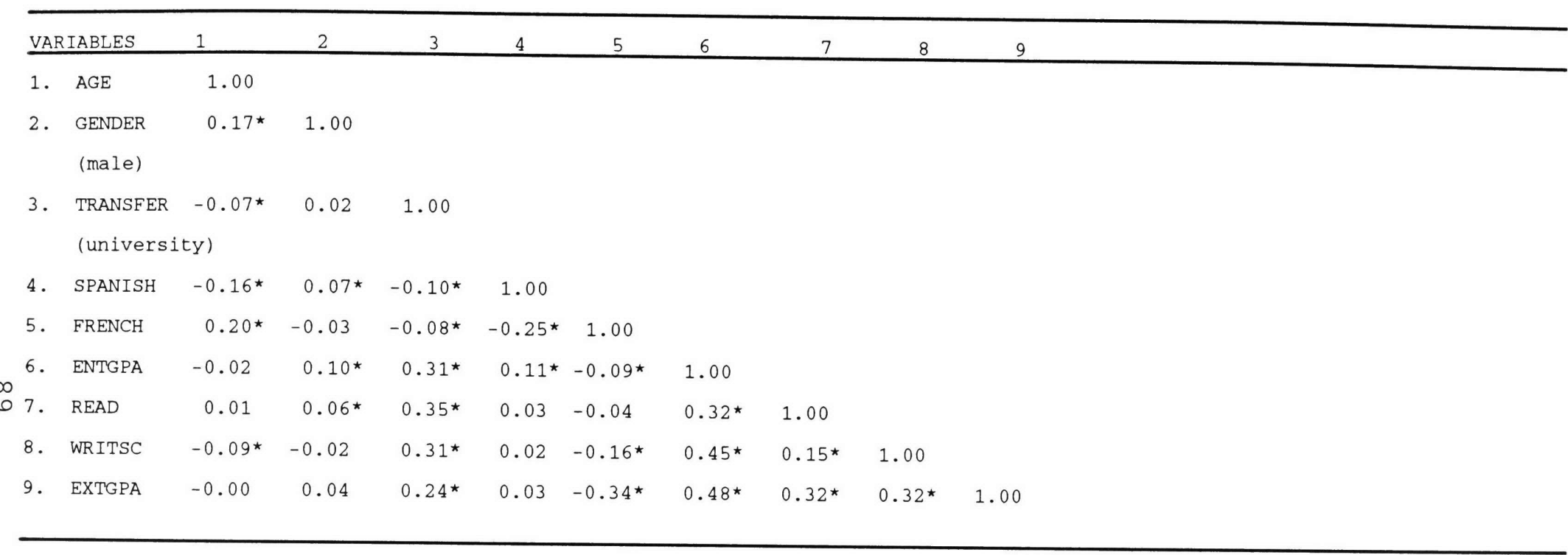

Note. All significant levels are based on a two-tailed test.

${ }^{\star} \mathrm{p}<.05$ 
CHAPTER 5

SUMMARY

This Ex Post Facto research utilized path analysis to test the use of Bloom's Learning Model in a sample of multicultural baccalaureate nursing students. Selected entry characteristics, reading and writing skills, and program exit grade point average were utilized to reflect the concepts of Bloom's Model.

The review of the literature in this topic area revealed the entry characteristics of transfer status, English as a Second Language, and entry grade point average (GPA) were characteristics investigated by previous nurse researchers and identified as variables placing the student "at risk" for program success. Reading and writing, the mediating basic skills in this model have also been explored in relation to college student's success.

A sample of 143 junior baccalaureate nursing students was investigated. The subjects completed a demographic questionnaire and reading and writing evaluations by Learning Laboratory faculty upon program entry. The results of these basis skills (reading and writing) evaluations, demographic data, and the program exit grade point average were analyzed for descriptive findings, correlation of variables, and a path analysis was conducted. 
Following the first stage of path analysis the nonsignificant paths were deleted and the analyses rerun to produce the trimmed preliminary model of program exit outcome. Decomposition of causal effects was performed. The correlation matrix was recreated without demonstrating multicollinearity utilizing the significant path variables only.

Path analysis was the method of statistical analysis. Results revealed exit GPA had shared variance with university transfer, French, (specifically Creole), entry GPA, reading score, and writing score in the correlation matrix. Spanish, French, entry GPA, reading score, and writing score were all significant variables in relationship to program exit grade point average or program outcome and directly affected program exit GPA. Age, male gender, entry GPA, and university transfer indirectly affected exit GPA by reading score. French, university transfer, and entry GPA indirectly affected exit GPA by writing score. The results supported Bloom's theory of learning.

\section{Discussion of Findings}

The path analysis utilized to test the Model of Program Exit Outcome revealed only some of the proposed paths contributed to the program outcome. These paths were from the variables of age, male gender, university transfer, and 
entry GPA to reading score and from the variables of university transfer, French, and entry GPA to writing score. Therefore, these variables identified as mediator variables, reading and writing scores, did have a significant relationship with some of the entry characteristics. Variables directly affecting exit GPA were Spanish, French, entry GPA, reading score, and writing score.

Only three negative path coefficients emerged. These negative paths were found with the variables Spanish and French. The paths between Spanish and French to exit GPA each had significant inverse coefficients, signaling nursing faculty in this program to the awareness of French or Spanish as a first language directly influencing the student's exit GPA. French as a first language also displayed a significant inverse coefficient when regressed with writing score. French directly affected exit GPA and also indirectly affected exit GPA by the mediator writing score. These meaningful inverse path coefficients support the notion that English as a Second Language (ESL) students may have difficulty conceptualizing nursing, particularly the student with French as a first language who is required to write professional papers and submit essay examinations. These findings are supported by Memmer and Worth (1991) who found obvious difficulties for ESL nursing students in the areas of reading, listening, and writing. This finding is 
also important to note when multicultural nursing students are not graduating from U.S. nursing programs in proportion to their representation in the population (Tucker-Allen, 1989).

The sample descriptive analysis revealed a diverse participant ethnicity. The Haitian students represented $10.5 \%$ of the study sample. The first language for this group of students was French or a dialect of French known as Creole. The path analysis revealed students for whom French, was a first language, had significant inverse coefficients in paths between French and writing score and French and exit GPA. This data and the deletion of two variables profiling many of this sample's characteristics which were female and community college transfer, supports the need for these findings to be reflected in the program's advisement role for students who may present this high risk profile. The female, community college transfer student for whom French was a first language had entry characteristics which were not associated with program exit outcome or basic skills in a positive path. The student profile demonstrating the highest exit GPA was the male university transfer student with high reading and writing scores and a high entry GPA.

The descriptive findings further revealed how very different this study sample was from the National League of 
Nursing's (NLN) description of baccalaureate nursing student in the area of race. Tale 15 compares the findings of this study to those of the NLN as these relate to a participant's race. This is interesting to note that the student of today in Florida public education is the student of tomorrow in the national education arena. This sample clearly represents the student of tomorrow.

Diversity is one of the goals of the $\mathrm{NLN}^{\prime} \mathrm{s}$ education agenda for the nineties (NLN, 1992). Previously cited literature indicates nursing schools have not done an adequate job of retaining and graduating multicultural nursing students from U.S. programs in proportion to their representation in the nation's population (Tucker-Allen, 1989). This preliminary findings of this path analysis may provide direction for this NLN goal. 
Table 15

A Comparison of Participant's Race to National Percentages

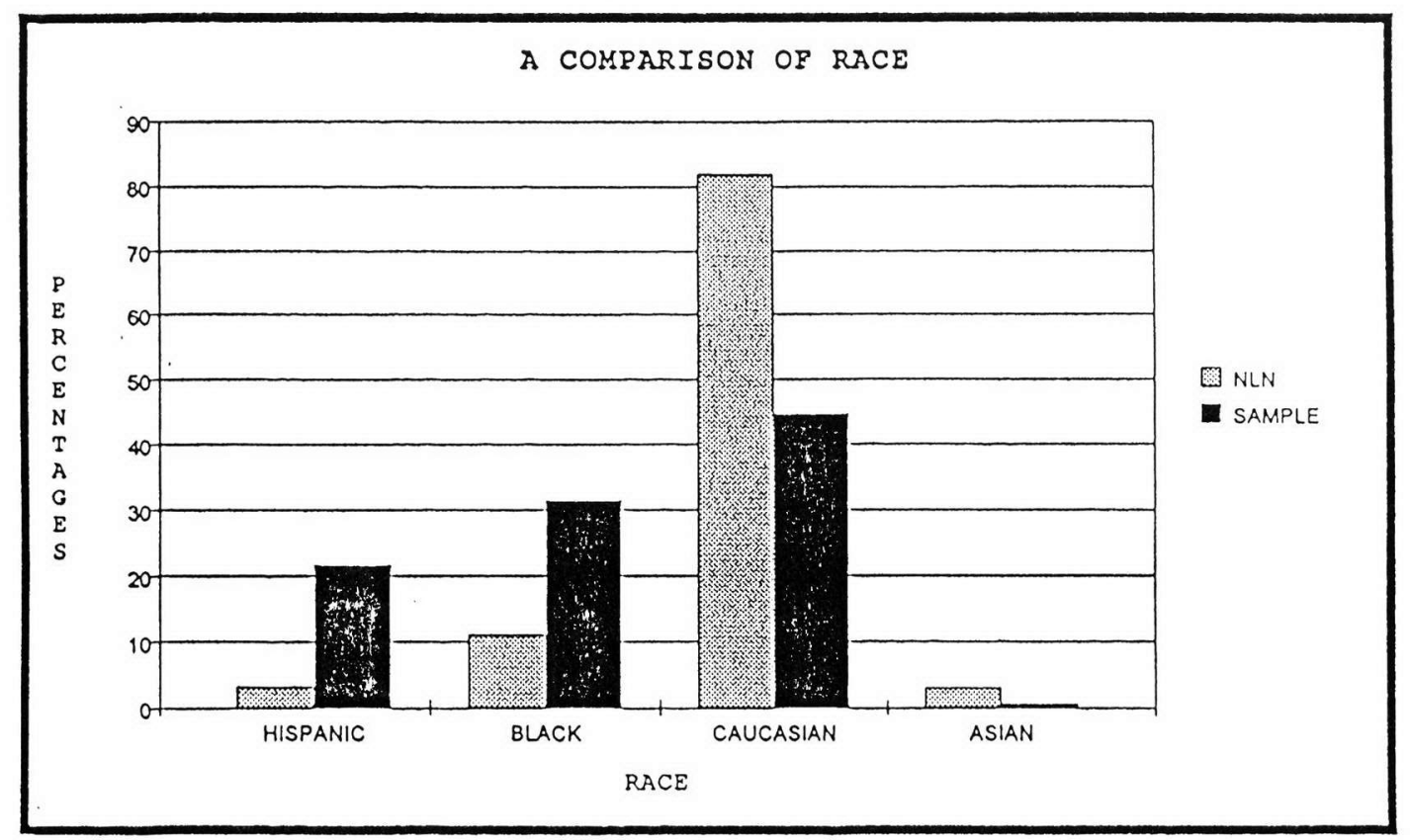




\section{Implications of the Study}

Path analysis findings for further discussion includes a breakdown of entry characteristics relation to exit GPA. Seven entry paths were related to exit GPA through basic skills. Only three entry paths were related to exit GPA directly. Therefore, in this preliminary model, the basic skills of reading and writing mediate specific entry characteristics of age, male gender, university transfer, French, and entry GPA in the entry characteristics relationship to program exit outcome.

Entry GPA was the only entry characteristic mediated by both reading and writing scores. Entry GPA emerged as the only entry characteristic significantly related to reading, writing, and exit GPA and accounted from the largest portions of variance in this model. The university transfer student with a high entry GPA has a better reading score, writing score, and exit GPA.

This finding emerged also in the literature review (see Table 2) where pre-nursing GPA was cited as the best indicator of nursing licensure in six of the 12 studies presented. Entry GPA as a predictor of success was cited frequently in relation to National Council Licensure Examination (NCLEX) success, the final goal of BSN completion. Entry GPA demonstrated a significant relationship with reading score, writing score, and exit GPA 
in this path analysis.

Age, male gender, and university transfer are all variables mediated by reading in their effect on exit GPA. The mean age of this sample was 24.7 years, there were 15 males, and only $22.7 \%$ of the sample were university transfer students. The path coefficients for these variables as they relate to reading were significant, although two were small in the contribution to the change of reading score. Age and male gender had minimal direct effects on reading score, however university transfer had the largest direct effect on reading score, followed by the variable entry GPA. These data may support the notion that community college transfer students (73.4\% of this sample) with poor or referral level reading skills are "at risk" for retention or failure within this program. This investigation was a preliminary study and further exploration of this relationship is needed.

Reading is important to assess for all entering students. This sample had an entry mean reading level of 8.55 (see Table 9). In contrast, the textbook readability analysis of the participants' nursing textbooks yielded a mean reading level of grade 11.8. Three of the four books analyzed had a reading level around the 11 th grade. The remaining textbook had a reading level at around 20 . Thus, it is apparent the students who comprised this sample for this study were required to read at a significantly higher 
level than the skill level demonstrated by the reading evaluations done by the Learning Laboratory faculty. The range of reading levels for this sample was from grade 2 to grade 17 (see Table 9). Faculty choice of textbooks appropriate for this population is needed. Appropriate student referral for the student who does not have the required skill is also recommended.

Writing score also mediated French and indirectly affected exit GPA. This inverse relationship signals educators to be aware that French as a first language in this sample indicated a lower writing score for these students. These findings signal the need to thoroughly assess the writing ability of entering students for whom French is a first language. These indirect effects of this path to exit GPA may require students with the combination of "at risk" writing scores and French as a first language to be remediated to aid successful program completion. French was inversely related to both writing score and exit GPA; therefore indicating a need to closely monitor the student with weak writing performance and French as a first language. Specifically, this student with these characteristics who presents with a entry GPA near the mean for those who have not graduated (2.488) and the student who has transferred from a community college. The number of students who spoke French, specifically Creole, were 24 of 
the 143 total sample participants. The percentage of these participants who did not graduate with the entry class was 58\%. The mean exit GPA for all non-French speaking students was 3.25. The mean exit GPA for those who spoke French was 2.9 and the overall exit GPA for the entire sample was 3.18 . The writing mean for the entire sample was 2.39 with $50.7 \%$ of the sample requiring referral to the writing laboratory for assistance in writing skills (see Table 10).

Finally exit GPA was directly affected by the paths of Spanish, French, entry GPA, reading score, and writing score. From the tables of the correlation matrices (see Table 11 and Table 14), these independent variables had shared variance as pairs in each of these correlation matrices with exit GPA. The significant path coefficients demonstrated between these variables in the trimmed model may have occurred due to the original shared variance between these pairs. However, French and entry GPA had direct effects on writing also. These findings imply there is an indirect relationship from these two paths of French and entry GPA to exit GPA. These variables have more than just shared variance as pairs, but rather an indirect causal effect on exit GPA. Table 13 revealed the indirect causal effect of French $(-.028)$ on exit GPA to be minimal. The indirect causal effect of entry GPA (.109) on exit GPA was significant. 
In summarizing the implications of this study, the predictor variable, entry GPA, accounted for the greatest direct effect in the mediator variables of reading and writing scores and the outcome variable program exit GPA. This finding supports the literature findings noted in relation to Table 2. Entry GPA is an important predictor of program success.

French or Creole, the primary language of the Haitian culture was inversely associated with writing score and program exit GPA. Students speaking this language at the primary language had lower writing scores and program exit GPAs. ESL students have been documented in this literature review to have more program completion difficulties than do non-ESL students. And finally the mediating variables of reading and writing demonstrated equal direct effects on program exit GPA and only the predictor variables, university transfer, and entry GPA, were mediated by both reading and writing scores. Writing score also mediated the predictor variable French and reading score mediated age, male gender, and university transfer. This study has implications for advisors who are advising students with these characteristics and implications for the advisor counseling students educated in another country. 
Recommendations for Further Study

The following are recommendations for future studies:

1. Replicate the study utilizing a similar, but different sample to determine if this preliminary model is program specific.

2. Replicate the study utilizing a reading evaluation tool with previously established reliability and validity. The instrument utilized in this study did not have previously established reliability; therefore, it is difficult to determine if the findings related to reading are valid. However, the writing scores and reading scores accounted for the same proportion of direct effects on the program exit GPA, that is $(.280)$.

3. Investigate the role specified nursing content knowledge has in the program exit outcome.

4. Replicate the study to include the mediating variables of writing score, reading score, and math score to include all basic skill variables.

5. Explore how the number of years of speaking English as a second language impacts program exit outcome. 
APPENDIX A

DEMOGRAPHIC DATA QUESTIONNAIRE 


\section{CIRCLE THE APPROPRIATE NUMBER .}

\section{DISREGARD THE NUMBERS IN PARENTHESES ( )}

Example: 1. Male() 2. Female()

1. Sex 1. Male(1) 2. Female(0)

2. Age 1. 20 and younger(1) 2. 20 to $30(0) \quad 3.31$ and older (0)

3. Marttal status 1. Single(1) 2. Divorced(1) 3. Married(0)

4. Race 1. Amer. Indian(1) 2. Asian(1) 3. Black(1) 4. Hispanic(1) 5. White (0)

5. Ethnic1ty 1. Africa(1) 2. Bahamas(1) 3. Cuba(1) 4. Haiti(1) 5. Indochina(1) 6. Jamaica(1) 7. Puerto Rico(1) 8. United States(0) 9. Other(1)

6. How many hours do you plan to be employed during the academic year? 1. 0 hours (0) 2. 1-10 hours(1) 3. 11-20 hours (2) 4. 21-30 hours (3) 5. 31 hours or more(4)

7. W11l you be employed in a health care facility? 1. Yes (0) 2. No(1) 3. Not Applicable (Not employed) (0)

8. Have you or are you planning to apply for tultion assistance during this academic year? 1 . Yes (1) 2 . No (0)

9. Are you a single parent? 1 . Yes(1) 2. No(0)

10. Number of children at home: 1. None (0) 2. One (1) 3. Two or more (2)

11. Ages of chlldren at home: 1 . No children(0). 2. Pregnancy (self/wife)5 years of age(2) 3. 6-12 years of age(1) 4. 13-18 years of age(1)

12. Do you have financlal responsiblitties for others (such as famtly members) than yourself? 1 . Yes (1) 2. No(0)

13. Were you born in the United States? 1 . Yes (0) 2. No(1)

14. How long have you IIved in the 0.s.? 1. Less than 5 years (2)

2. 5-10 years (1) 3. More than 10 years $(0)$

4. Not Applicable (Born in U.S.) (0)

15. Since elementary school, have you attended school in other countries (outside United states) for two years or more? 1 . Yes(1) 2 . No(0)

16. Is English a second language for you? 1 . Yes (1) 2. No(0)

17. Approximately what percentage of the time do you speak English outside

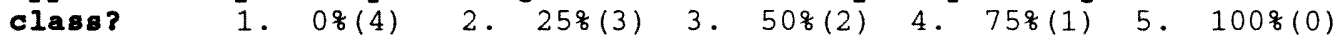

18. English 18 a second language for you. Please rate your current ab1lity with Bnglish for your university work: N.A. = English is your first language.

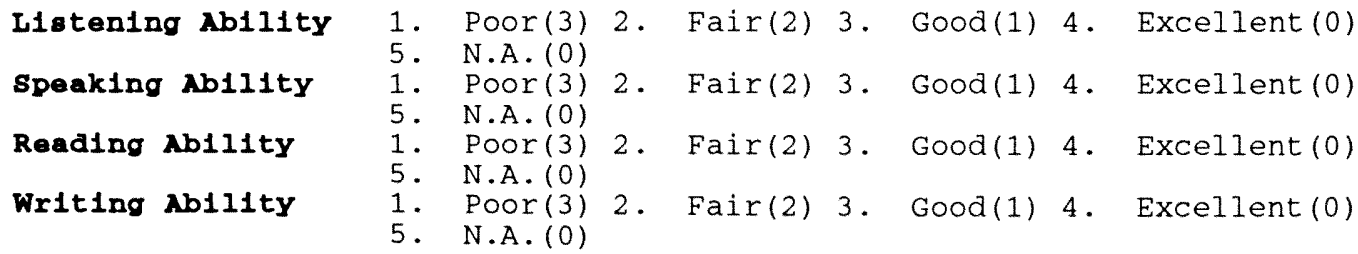


19. GPA (Cumulative)

20. GPA (sclence courses only-cumulative)

Chemistry
Anatomy
Physiology
Microbiology

1. $2.00-249(3) 2.2 .50-2.99(2) \quad 3.3 .00-3.49(1) \quad 4.3 .50-4.00(0)$

21. Withdrawals/Failures in nursing prerequisite courses
1. 3 or more( 3
2. $2(2)$
3. $1(1)$
4. $0(0)$ 
APPENDIX B

READING AND STUDY SKILLS INVENTORY

105 


\section{READING AND STUDY SKILLS INVENTORY}

\section{Assessment 1: College Study Demands}

In the space provided, place a $\mathbf{T}$ if the statement is true and an $\mathbf{F}$ if the state is false.

1. The two factors that best differentiate between good and poor students are: (1) good study habits (2) interest.

2. Studying can make you tired.

3. Student taking three core courses in a term average about 100 pages of reading a week.

4. The more details you can memorize from the textbook, the better you will do on exams.

5. Reviewing material more than triples your memory for it.

6. If you know the material in the textbook, you do not have to pay as much attention during lectures.

7. Given enough study time, almost any student can perform at the top of the class.

8. On the average, students have about ten hours a day of free time (time not spent in class, studying, eating, or sleeping).

9. You should read most materials (such as newspapers, novels, and textbooks) at about the same rate of speed. 
10. In the figure below, try to connect the nine dots by drawing four straight lines without taking the pencil from the paper.

-

-

-

-

0 
1. Do you usually pick up a book, magazine, or newspaper and begin to read immediately, without considering your purpose?

2. As you read, does every statement seem equally important?

3. Do you point to words with your finger or move your lips as you read?

4. Do you ever skip or reread a line?

5. Do you ever go back to reread a phrase or sentence you have already read?

6. If you find an unfamiliar word in your reading, do you skip over it?

7. Do you ever confuse words like compliment and complement?

8. Do you have difficulty defining the main idea in a passage?

9. Do you have difficulty remembering telephone numbers that you have just looked up?

10. Do you ever discover that you remember no details of a magazine article you read last week?

11. Do you read everything at the same rate

\section{Group II}

1. Are you aware of punctuation marks as you read?

2. Do you own a good dictionary, and do you refer to it often? 
3. Can you rapidly locate the main thought in a long, involved sentence?

4. Can you follow and summarize the train of thought as you read a long selection?

5. Can you glance rapidly over a long selection?

6. Do you ever underline or make notes as you read?

7. Is it easy for you to glance down an alphabetized list and locate rapidly the exact word or name that you want?

8. Do paragraph breaks seem significant to you when you are reading?

9. Can you extract the main facts of a long news article in a few minutes?

10. do you ever notice a lack of logic in the articles or editorials you read?

11. Can you distinguish between fact and opinion?

12. Do you known how the books in your local library are arranged?

13. Do you know the standard parts of a book (glossary, table of contents, appendix, bibliography, and so on)?

14. If you know the parts of a book, do you know how to use them?

15. Can you explain exactly why you liked or disliked a story you read recently? 


\section{SOME \\ YES TIMES NO}

1. I adjust my rate according to the type

of material I am reading.

2. I look through a chapter before reading

it.

3. I underline or highlight while I am reading.

4. I have a difficult time maintaining concentration for a period of time

5. I tend to cram for major tests.

6. I understand my notes weeks after I have taken them.

7. I plan study sessions well in advance of a major exam.

8. I use a variety of study techniques.

9. I can use the proper strategies for specific content areas.

10. I read an entire chapter before stopping to think about it.

11. I can distinguish important from unimportant information.

12. To prepare for a test, I try to memorize lots of facts.

13. I have little trouble with content-specific vocabulary

14. I try to predict items that an instructor might ask on a test. 
15. I do well only in subjects that interest me.

16. I get extremely anxious during test.

17. I have a systematic method for taking lecture notes.

18. I take detailed notes from my text while I am reading.

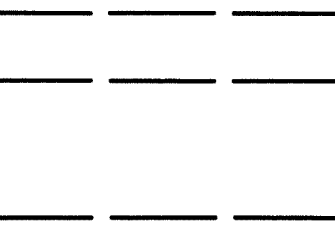

ded notes from my text while I am reading. 
APPENDIX C

PRACTICE ESSAY 
You will have 60 minutes to plan, write, and proofread an essay on one of the topics below.

TOPICS: 1 . Discuss a political or social organization that has helped or harmed the world.

2. What product should be taken off the market and why?

Read the two topics again and select the one on which you wish to write your essay. In order for your essay to be scored. It must be on only one of these topics.

In your essay, you should introduce the subject and then either

_explain the subject you have chosen, or

_take a position about your subject and support it. At least two evaluators will read your essay and assign it a score. They will pay special attention to whether you have a clear thesis or main idea, develop your thesis logically and in sufficient detail,

_use well-formed sentences and paragraphs,

_use language appropriately and effectively, and

follow standard practices in spelling, punctuation, and grammar.

Take a few minutes to think about what you want to say before you start writing. Leave yourself a few minutes at 
the end of the period to proofread and make corrections. You may cross out or add information as necessary. Although your handwriting will not affect your score, you should write as legibly as possible so that the evaluators can easily read your essay.

You may use the following page to plan your essay before you begin to write in the answer folder. Do not begin until you are told to do so. 
APPENDIX D

LETTER TO BILL FISHER 
PATRICIA ALLEN, RN, MSN

Doctoral Student

College of Education

Florida International University

Miami, Florida

May 17, 1994

Bill Fisher

Research Technician

College of Nursing

The University of Oklahoma

Oklahoma City, Oklahoma

Dear Mr. Fisher:

I am writing to thank you for your support in the data entry of my dissertation. I appreciate the time and effort you have taken to validate my data input for the statistical analysis of my dissertation path model.

Your role was invaluable in enabling me to complete my data analysis. Again, I would like to thank you.

Sincerely,

Patricia Allen, RN, MSN

Doctoral Candidate, FIU

Clinical Assistant Professor, OUCN

CC: Pat Forni, Dean OUCN 
APPENDIX E

LETTER TO DR. LA GROW 
PATRICIA ALLEN, RN, MSN

Doctoral Student

College of Education

Florida International University

Miami, Florida

May 17, 1994

Pat LaGrow

Assistant Professor

The University of Central Oklahoma

Edmond, Oklahoma

Dear Dr. LaGrow:

I would like to thank you for agreeing to consult on my dissertation data analysis. as you have recently completed a path analysis project, I know your insight and support will be quite valuable in the outcome of this analysis.

Sincerely,

Patricia Allen, RN, MSN

Doctoral Candidate, FIU 
Allen, D., Bowers, B., \& Diekelmann, N. (1989). Writing to learn: A reconceptualization of thinking and writing in the nursing curriculum. Journal of Nursing Education, 28(1), 6-11.

Allen, P., Ellis, A., \& Northrop, C. (1992). Screening and tracking of multicultural baccalaureate nursing students. Toward a Healthier Florida: Innovations in Nursing Practice and Education, Florida League of Nursing.

Ashley, J., \& O'Neil, J. (1991). The effectiveness of an intervention to promote successful performance on NCLEX-RN for baccalaureate students at risk for failure. Journal of Nursing Education, $\underline{30}$ (8), 360-366.

Astin, A. (1975). Preventing students from dropping out. San Francisco: Jossey Bass.

Bean, J. (1980). Dropouts and turnover: The synthesis and test of a causal model of student attrition. Research in Higher Education, 12, 155-187.

Bean, J. (1982). Student attrition, interactions, and confidence: Interaction effects in a path model. Research in Higher Education, 17, 291-320.

Benda, E. (1991). The relationship among variables in Tinto's conceptual model and attrition of bachelor's degree nursing students. Journal of Professional Nursing, $7(1), 16-24$.

Bevis, O., \& Watson, J. (1989). Toward a caring curriculum: a new pedagogy for nursing. New York: National League for Nursing.

Blalock, (1971). Causal models in the social sciences. Chicago: Aldine.

Bloom, B. (1976). Human characteristics and school learning. New York: McGraw-Hill Book Company.

Bloom, B., Hastings, J., \& Madaus, G. (1971). Handbook on formative and summative evaluation of student learning. New York: McGraw-Hill Book Company. 
Bosma, J. (1990). National Council Licensure Exam. Nurse Educator, $15(2), 42$.

Bradley-Springer, L. (1993). Discovery of meaning through imagined experience, writing, and evaluation. Nurse Educator, 18, (5), 5-10.

Brazeman, C. (1981). What written knowledge does: Three examples of academic discourse. Philosophy and Social Science, 11(3), 361-387.

Campbell, A., \& Davis, S. (1990). Enrichment for academic success: Helping at-risk students. Nurse Educator, $15(6), 33-37$

Carpenito, L. (1992). Nursing diagnosis: Application to clinical practice. Philadelphia: J. B. Lippincott Company.

Cella, J. \& Watson, J. (1989). Nurses manual of laboratory tests. Philadelphia: F. A. Davis Company.

Chacko, S., \& Huba, M. (1991). Academic achievement among undergraduate nursing students: The development and test of a causal model. Journal of nursing Education, $\underline{30}(6), 267-273$.

Clowes, D. (1980). More than a definition problem: remedial, compensatory, and developmental education. Journal of Developmental and Remedial Education, 4 (1), 11-17.

Cohen, J. (1987). Statistical power analysis for the behavioral sciences. Hillsdale, NJ: Lawrence Erlbaum Associates.

Colombraro, G. (1990). NCLEX-RN preparation: Enabling candidatesto pass. The Journal of Continuing Education in Nursing, 20 $(6), 261-267$.

Dell, M., \& Valine, W. (1990). Explaining differences in NCLEX-RN scores with certain cognitive and noncognitive factors for new baccalaureate nurse graduates. Journal of Nursing Education, 29(4), 158-162.

Farrand, L., \& Cox, C. (1993). Determinants of positive health behavior in middle childhood. Nursing Research, $\underline{42}(4), 208-213$. 
Farrell, J. (1988). The changing pool of candidates for nursing. Journal of Professional Nursing, 4 (3), 145.

Feldt, R., \& Donahue, Sir. M. (1989). Predicting nursing GPA and National Council Licensure Examination for Registered Nurses (NCLEX-RN) : A thorough analysis. Psychological Reports, 64, 415-421.

Foti, I., \& DeYoung, S. (1991). Predicting success on the National Council Licensure Examination-Registered Nurse: Another piece of the puzzle. Journal of Professional Nursing, 7(2), 99-104.

Fowles, E. (1992). Predictors of success on NCLEX-RN and within the nursing curriculum: Implications for early intervention. Journal of Nursing Education, 31(2), 53-57.

Froman, R., \& Owen, S. (1989). Predicting performance on the National Council Licensure Examination. Western Journal of Nursing Research, 11(3), 334-346.

Gittelsohn, J. (1993, May). Writing test scores poor among 4th-8th-graders. Sun-Sentinel, p. 6B.

Glick, O., MCClelland, E., \& Yang, J. (1986). NCLEX-RN : Predicting the performance of graduates of an integrated baccalaureate nursing program. Journal of Professional Nursing, $\underline{2}(2), 98-103$.

Hawkes, J., \& Holm, K. (1993). Gender differences in exercise determinants. Nursing Research, $\underline{42}(3)$, 166-172.

Hayduk, L. (1987). Structural equation modeling with LISREL. Baltimore: The John Hopkins University Press.

Heinrich, K. (1992). The intimate dialogue: Journal writing by students. Nurse Educator, 17(6), 17-20.

Higgs, Z. (1984). Predicting success in nursing: From prototype to pragmatics. Western Journal of Nursing Research, $\underline{6}(), 77-93$.

Horns, P., O'Sullivan, P., \& Goodman, R. (1991). The use of progressive indicators as predictors of NCLEX-RN success and performance of BSN graduates. Journal of Nursing Education, 30(1), 9-14. 
Huch, M., Leonard, R., \& Gutsch, K. (1992). Nursing education: Developing equations for selection and retention. Journal of Professional Nursing, 8 (3), 170-175.

Ignatavicius, Donna, \& Bayne, M. (1991). Medical-surgical nursing: A nursing process approach. Philadelphia: W. B. Saunders.

Johanson, C. , \& Rossman, J. (1973). Persistence at a liberal arts college: A replicated five-year longitudinal study. Journal of Counseling and Psychology, 20, 1-9.

Johnson, J., Ratner, P., Bottorff, J., \& Hayduk, L. (1993). An exploration of Pender's health promotion model using LISREL. Nursing Research, 42(3), 132-138.

Johnstone, J. (1989). Changing demographics in New York State: Implications for nursing education and practice. Journal of the New York State Nurses Association, 20(2), 7-15.

Kenny, D. (1979) . Correlation and causality. New York: Wiley

Kinneavy, T. (1980). A theory of discourse. New York: Norton

Kleindienst, L., Rubin, J., \& Cenziper, D. (1993, June) . Ethnic mix called factor in S. Florida School test scores. Sun-Sentinel, p. 4B.

Kozier, B., Erb, G., \& Olivieri, R. (1991). Fundamentals of nursing. Menlo Park: Addison-Wesley.

Lash, A. (1992). Determinants of career attainments of doctorates of nursing. Nursing Research, 41(2), $216-222$.

Lee, V., \& Frank, K. (1990). Student characteristics that facilitate the transfer from two-year to four-year colleges. Sociology of Education, 63(3), 178-192.

Larose, S., \& Roy, R., (1991). The role of prior academic performance and nonacademic attributes in the prediction of success of high-risk college students. Journal of College Student Development, 32, 171-177. 
Levin, M. \& Levin, J., (1991). A critical examination of academic retention programs for at-risk minority college students. Journal of College Student Development, $32,323-333$.

Lindley, P., \& Walker, S. (1993). Theoretical and methodological differentiation of moderation and mediation. Nursing Research, $\underline{42}(5), 276-279$.

McClelland, E., Yang, J., \& Glick, O. (1992). A statewide study of academic variables affecting performance of baccalaureate nursing graduates on licensure examination. Journal of Professional Nursing. $8(6)$, $342-350$.

McCord, M., (1985). Methods of theory and instruction. In J. C. Smart (Ed.), Higher education: handbook of theory and research (pp. 97-131), New York: Agathon Press, Inc.

Mckinney, J., Small, S., O’Dell, N., \& Coonrod, B. (1988). Identification of predictors of success for the NCLEX and students at risk for NCLEX failure in a baccalaureate nursing program. Journal of Professional Nursing, $\underline{4}(1), 55-59$.

Memmer, M., \& Worth, C. (1991). Retention of ESL students: Approaches used by California's 21 generic baccalaureate nursing programs. Journal of Nursing Education, 33(9), 389-396

Moccia, P. (1989). 1989: Shaping a human agenda for the nineties, trends that demand our attention as managed care prevails. Nursing \& Health Care, 10(1), 15-17.

Munro, B. (1991). Measuring relationships. Clinical Nurse Specialist $\underline{5}(3), 143-150$.

Munro, B. (1981). Dropouts in higher education: Path analysis of a national sample. American Educational Research Journal, 18, 133-141.

Munro, B., \& Page, E. (1986). Statistical methods for health care and research. Philadelphia: J. B. Lippincott $\mathrm{Co}$. 
Nakanishi, D. (1990). Asian Americans and adult education: The social and political resocialization of a diverse immigrant and refugee population. In B. Cassera (Ed.) Adult education in a multicultural society. Rutledge: Chapman and Hall.

National Commission on Educational Excellence in Education, 1983. A nation at risk: The imperative for educational reform. Washington, DC: U.S. Department of Education.

National League for Nursing. (1992). An agenda for nursing education reform (position paper). New York: Author.

NCLEX Summary Profile (1993). Monterey: MacMillan/McGraw$\mathrm{Hill}$.

Nie, H. (1975). User's Guide for SPSS. New York: McGrawHill Book Co.

Nist, S. and Diehl, W., (1985). Developing textbook thinking. Lexington: D.C. Heath and Company.

Norusis, M. (1988). SPSS/PC+: Studentware. Chicago: SPSS Inc.

Odell, L. (1980). The process of writing and the process of learning. College Composition and Communication $31(1)$, 42-50.

Pascarella, E., \& Chapman, D. (1983). A multiinstitutional path analytic validation of Tinto's model of college withdrawal. American Educational Research Journal, 20, 87-102.

Payne, M. \& Duffy, M. (1986). An investigation of the predictability of NCLEX scores of BSN graduates using academic predictors. Journal of Professional Nursing, $\underline{2}(5), 326-332$.

Pedhazaur, E. (1982). Multiple regression in behavioral research. Fort Worth: Holt, Rinehart and Winston.

Phillips, S., \& Hartley, J. (1220). Teaching students for whom English is a second language. Nurse Educator, $15(5), 29-32$.

Polit, D., \& Hungler, B. (1991). Nursing research: Principles and methods. Philadelphia: J. B. Lippincott Company. 
Quick, N., Krupa, K., \& Whitley. T. 1985). Using admission data to predict success on the NCLEX-RN in a baccalaureate program. Journal of Professional Nursing, $1(4), 364-367$.

Ratcliff, J. (1992). Using assessment as a basis for the articulation of transfer students. New Directions for Higher Education, 80, 47-67.

Redman, B. (1986). Enrollment update: Comparison of fall 1984 and 1985 enrollments in AACN member schools with trends in higher education enrollments. Journal of Professional Nursing, $\underline{5}(1), 129-132$.

Ross-Gordon, J. (1991). Needed: A multicultural perspective for adult education research. Adult Education Quarterly, $\underline{42}(1), 1-16$.

Shearer, R. (1989). Teaching foreign students. Journal of Nursing Education, 28(9), 427-428.

Slimmer, L. (1992). Effect of writing across the curriculum techniques on students' affective and cognitive learning about Nursing Research. Journal of Nursing Education, 31(2), 75-78.

Sorrell, J. (1991). The composing processes of nursing students in writing nurses' notes. Journal of Nursing Education, 30(4), 162-167.

Spady, W. (1970). Dropouts from higher education: An interdisciplinary review and synthesis. Interchange, 1. 64-85.

Stage, F., \& McCafferty, P. (1992). Nontraditional and traditional students in the college mathematics classroom. NASPA Journal, 29(2), 101-106.

Symons, S. \& Pressley, M. (1993). Prior knowledge affects text search success and extraction of information. Reading Research Quarterly, 28(3), 251-258.

Technical Report. (1991). College Level Academic Skills Test (CLAST). Department of Education. Tallahassee: State of Florida.

Thompson, C., \& Crutchlow, E. (1993). Learning style research: A critical review of the literature and implications for nursing education. Journal of Professional Nursing, $\underline{9}(1), 34-40$. 
Tinto, V. (1975). Dropout from higher education: A theoretical synthesis of recent research. Review of Educational Research, 45, 89-125.

Tomlinson, S. (1990). Writing to learn: Back to another basic. New Directions for Teaching and Learning, 42, $31-39$.

Tucker-Allen, S. (1989). Losses incurred through minority student nurse attrition. Nursing and Health Care, 10 , (7), 395-397.

U. S. Department of Education, Office of the Assistant Secretary for Educational Research and Improvement, (1990). Collegebound seniors: SAT score averages 1969-1990. Washington, DC: Author.

Wall, B., Miller, D., \& Widerquist, J. (1993). Predictors of success on the newest NCLEX-RN. Western Journal of Nursing Research, 15(5), 628-643.

Waterhouse, J., Carroll, M., \& Beeman, P. (1993). National council licensure examination success: Accurate prediction of student performance on the post-1988 examination. Journal of Professional Nursing, 9(5), $278-283$.

Whitley, M., \& Chadwick, P., (1986). Baccalaureate education and NCLEX: the causes of success. Journal of Nursing Education, 25(3), 94-101.

Wolahan, C., \& Weiczorek, R. (1991). Enrichment education: Key to NCLEX success. Nursing \& Health Care, 12(5), 234-239.

Wolfe, L. (1985). Application of causal models in higher education. In J. C. Smart (Ed.), Higher education: Handbook of theory and research (pp. 381-413). New York: Agathon Press, Inc.

Wright, S. (1921). Correlational and causation. Journal of Agricultural Research, 20, 557-585.

Yang, J., Glick, O., \& McClelland, E. (1987). Academic correlates of baccalaureate graduate performance on NCLEX-RN. Journal of Professional Nursing, 3 (5), 298306 .

Younger, J., \& Grap, M. (1992). An epidemiologic study of NCLEX. Nurse Educator, 17(2), 24-28. 
October 27,1953

1976

$1976-1978$

1980

$1980-1983$

1984-1989

1989-1993

1993-Present
Born, Alexandria, Virginia

B.S., Nursing

old Dominion University

Norfolk, Virginia

DePaul Hospital

Norfolk, Virginia

M.S.N., Medical-

Surgical Nursing

The Catholic University

of America

Washington, D.C.

Instructor, The University of Oklahoma

College of Nursing

Oklahoma City, Oklahoma

Assistant Professor, Piedmont Virginia Community College of Nursing Charlottesville, Virginia

Assistant Professor, Florida International University, School of Nursing Miami, Florida

Assistant Professor, The University of Oklahoma College of Nursing

Oklahoma City, Oklahoma

\section{PUBLICATIONS AND RESEARCH}

Leasure, R., Allen, P., and LaGrow, P. (1994). Women living with AIDS: The invisible participant. Grant submitted for and funding May 1994.

Leasure, R., Allen, P., West, A., and LaGrow, P (1994) Attitudes of Oklahoma health care providers toward persons living with AIDS. Grant in progress funded by the Oklahoma Nurses Foundation. 
Leasure, R., Allen, P., and West, A. (1994). Stigma:

Attitudes of baccalaureate nursing students toward persons living with AIDS. Grant in progress funded by Sigma Theta Tau Beta Delta Chapter.

Leasure, R. and Allen, P. (1994). Overview of the Research Process. In Talbot, L. Principles and Practice of Nursing Research. St. Louis: C. V. Mosby Co. (in press).

Allen, P., Ellis, A., and Northrop, C. "Screening and Tracking of Multicultural Baccalaureate Nursing Students," Toward a Healthier Florida: Innovations in Nursing Practice and Education. Florida League of Nursing, January, 1992 .

Fehring, R., Allen, P., and Chandler, E., "The Effects of a College Stress Management Program on Blood Pressure," The American Journal of Nursing, March 1983.

Porter, B., Allen, P. and Edwards, K. "The Effect of a Short-term Psychophysiological Examination of Guided Imagery and Progressive Relaxation Procedures on Blood Pressure." Presented on October 30, 1981 at the Fourth annual Research Conference VAMC, Chicago and at the VAMC Research Forum, September, 1981, OKC, OK. Dean's Office Funding.

Fehring, R., Allen, P. H., and Chandler, E. L. Behavioral Management of Clients at Risk for Hypertension: The effect of Biofeedback-Aided Relaxation on Blood Pressure. Research funded by a grant from the American Heart Association and presented at the Second Annual Research Conference, "Leadership in Nursing Through Research" sponsored by Sigma Theta Tau, Kappa, Spring 1980 . 